\title{
LA PANADERÍA DE LA CALLE AVINYÓ Y EL ARTESANADO TARDORROMANO EN LA CIUDAD DE BARCINO (BARCELONA)
}

\author{
THE BAKERY OF AVINYÓ STREET AND THE LATE ROMAN \\ CRAFTS IN THE CITY OF BARCINO (BARCELONA)
}

\author{
JOSEFA HUERTAS ARROYO* / YOLANDA PEÑA CERVANTES** / CARME MIRO ALAIX***
}

Resumen: En este trabajo presentamos el hallazgo de los restos de una panadería de época tardorromana, excavada en la intervención de la calle Avinyó, en el casco histórico de Barcelona. Se ha documentado parte de un horno de calentamiento directo, de forma cuadrangular y estructura interna circular con cubierta cupulada, que presenta en su frontal un molino harinero, procedente de las canteras de Orvieto, que aparece, volteado y vaciado, reutilizado como contenedor. En la segunda parte de este trabajo procedemos al análisis de las evidencias productivas localizadas en la Colonia Barcino, tanto intramuros como en su suburbium próximo, coetáneas a los restos documentados en la Domus de Avinyó.

Palabras clave: Barcelona, Barcino, artesanado, panadería, vino, perfumes, cereal.

\section{INTRODUCCIÓN}

El origen de Barcelona como ciudad, no como territorio habitado, debemos buscarlo en la pequeña colonia que el emperador Octavio Augusto fundó hacia el año 10 a.C., ex novo, y que recibió el nombre de colonia

\footnotetext{
* Arqueóloga. Correo-e: josefa.huertas@gmail.com.

** UNED/ICAC. UNED, Facultad de Geografía e Historia. Paseo Senda del Rey, 7.28040-Madrid. Correo-e: yolandapcervantes@ geo.uned.es.
}

\begin{abstract}
This article presents the find of part of a late Roman bakery located at the Avinyó Street in the ancient quarter of the city. Part of a furnace has been documented. The furnace is a direct heating of square-shaped type and circular internal structure with domed cover, presenting on its front a mill flour, from the quarries of Orvieto, which appears, flipped and emptied, reused as a container.

In the second part of this article we carry out analysis of the productives evidences locates in the Colonia Barcino, both inside the walled area as in the nearest suburbium, contemporaries to the ones documented in the domus Avinyó.
\end{abstract}

Keywords: Barcelona, Barcino, crafts, bakery, wine, perfume, cereal.

Iulia Augusta Faventia Paterna Barcino, que nació ya con una clara función administrativa y comercial, que le confirió una fisonomía propia.

Desde hace cuatro años se está trabajando en el marco del Plan Barcino, para sacar a la luz la colonia romana y dar a conocer los restos conservados y los

*** Servicio de Arqueología del Ayuntamiento de Barcelona. ICUB. Ayuntamiento de Barcelona. C/ Rull, 4. Barcelona 08002. Correo-e: cmiro@bcn.cat. 
conocidos arqueológica o documentalmente. El pasado romano ha dejado una huella en la actual ciudad de Barcelona, en según qué lugares muy viva, en otros muy escondida. Por ello se quiere dar a conocer Barcino, con un lema: "generando ilusión en la ciudad a partir de la arqueología”. En el marco de este Plan, se ha llevado a cabo la musealización de los restos de la Domus Avinyó, una casa de una familia acomodada de la colonia, lo que ha comportado un análisis en profundidad y un estudio de los diferentes elementos documentados.

\section{LA PANADERÍA DE LA CALLE AVINYÓ}

Entre los meses de junio del 2003 y julio del 2004 se realizó una intervención arqueológica de carácter preventivo, motivada por la rehabilitación arquitectónica del antiguo edificio municipal de Hacienda, ubicada en la calle Avinyó, 15. Esta intervención, dirigida por Adriana Vilardell (Vilardell 2006), permitió recuperar una secuencia de ocupación que abarca desde finales del siglo I a.C. hasta el siglo XX. Los restos datados en época romana son los más significativos, ya que se documentó parte de una domus y un tramo del intervallum, así como el paramento y la cimentación de una de las torres de la muralla bajoimperial de la ciudad (vid. fig. 1). La importancia de los restos romanos propició la conservación y posterior musealización de los mismos, dentro del Plan Barcino. El proyecto arquitectónico es del estudio VORA y el museográfico, de STOA, dirigido todo desde del Servicio de Arqueología de Barcelona, que también coordino las intervenciones arqueológicas asociadas al proceso, dirigidas por Josefa Huertas. Así mismo, se ha podido llevar a cabo la restauración del conjunto pictórico, el más importante documentado hasta el momento en Barcelona, por parte de la empresa ABAC bajo la dirección de Lídia Font, del Museo de Historia de Barcelona.

La insula donde se localiza esta domus se sitúa en el lateral meridional de la ciudad, en contacto con uno de los quiebros de la muralla, lo que establece una forma no estrictamente ortogonal para la construcción de los muros internos de la vivienda. Este hecho se puede apreciar en las diferentes orientaciones de algunos muros y en las líneas maestras de los pavimentos, especialmente en el caso de los pavimentos de mosaico y opus sectile.

Se han establecido un mínimo de tres fases constructivas para esta domus (Cortés 2011, Fernández y Suárez 2014, Huertas 2015, Vilardell 2006, Vilardell 2008), cuya amortización definitiva se fecha a finales del siglo
IV d.C. En la intervención se han documentado tres ámbitos, localizados en el límite sureste de la domus, junto a la fachada que delimita el intervallum pero sin conexión con este (ver fig. 2). La decoración de las diferentes estancias ha permitido identificarlas como un triclinium y un cubiculum. El espacio triclinar está formado por dos ámbitos unidos, pavimentados respectivamente con opus sectile y mosaico y con sus paredes decoradas con pintura mural. Estos dos ámbitos en un principio conformaban un espacio único separado por columnas, describiendo la cámara y la antecámara. A mediados del siglo III d.C., el gran espacio se compartimenta en dos habitaciones mediante un muro de adobe, que también conserva restos de una decoración pictórica muy sencilla. El cubiculum, pavimentado con opus signinum, se caracteriza, sin embargo, por una rica decoración pictórica (Fernández y Suárez 2013), donde destaca el techo de la habitación con la representación del rapto de Ganimedes. Estas decoraciones están datadas entre finales del siglo I y principios del II d.C., básicamente en función de sus elementos estilísticos.

De las fases constructivas anteriores a estas estancias, la información disponible es muy escasa, ya que no se ha procedido al levantamiento de los pavimentos que suelan estas habitaciones. Hemos podido documentar, sin embargo, elementos estructurales que indican una secuencia de ocupación desde el momento fundacional de la ciudad, en época augustea, tanto en la zona del intervallum como de la domus. A esta fase inicial pertenece, por ejemplo, una estructura de combustión localizada en el perfil de un pozo, amortizado a finales del siglo V o principios del VI d.C., que se realiza en época tardorromana en el ámbito originalmente utilizado como triclinium.

En la zona del intervallum, se localizaron diferentes niveles de uso y repavimentación, junto a una canalización de desagüe que parte de la domus. Del momento inicial de la colonia se han documentado un par de bases de pilares que podrían interpretarse como evidencias de la existencia de una calle porticada. Al igual que sucede en otras zonas de la ciudad, el espacio del intervallum es ocupado posteriormente por edificaciones privadas, como veremos más adelante. En este caso, con la construcción de un complejo productivo cuya cronología apunta a la segunda mitad del siglo III o inicios del siglo IV d.C., a partir de la fecha post quem aportada por los materiales del último de los niveles de pavimentación de la calle, donde se han recuperado escasos elementos cerámicos significativos, entre los que destaca algún fragmento de TSA C de la forma Hayes 50, fragmentos de ánforas africanas Keay IV y 


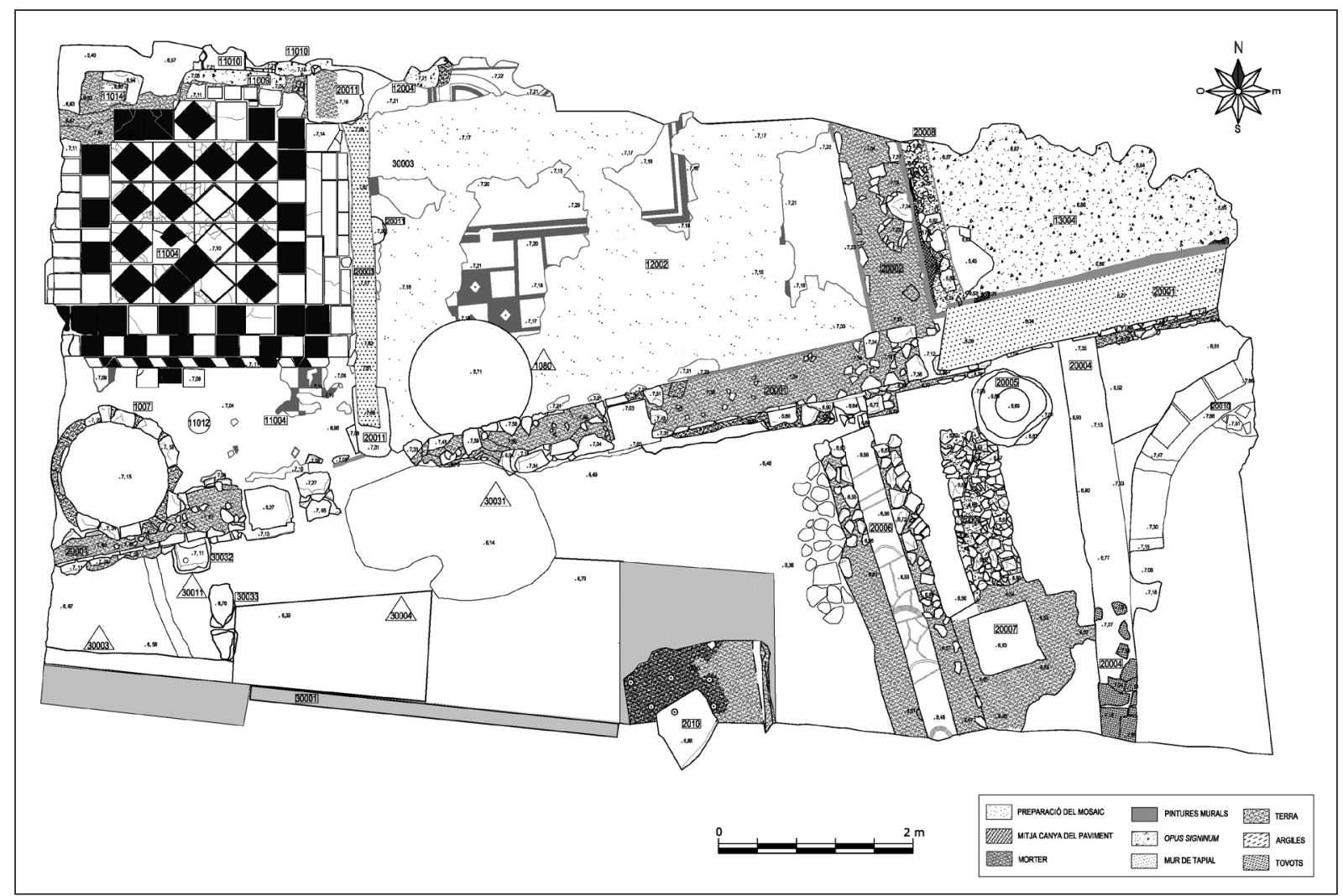

Figura 1. Planta de los restos documentados en la calle Avinyó, 15.

cerámica paleocristiana pintada $(\mathrm{CN}-\mathrm{ENG} \mathrm{B} 4)$ junto a monedas, entre ellas una de Iulia Mamaea Augusta (190-235 d.C.).

Este espacio productivo está situado en una zona periférica de la ciudad, entre la fachada posterior de la domus y la muralla, habiéndose documentado solo de forma parcial, ya que sobrepasa los límites de la zona excavada. Este hecho, junto a la alteración posterior de los vestigios de época tardorromana, debido a la ocupación continuada del solar, dificultan la interpretación funcional de los restos, que parecen pertenecer a una panadería. El espacio porticado original dará paso, por tanto, a la ocupación de la vía con la construcción de un enclave artesanal del que conocemos la presencia de un muro de adobe, los restos de un horno circular y la reutilización de una meta de un molino harinero como contenedor.

El muro de adobe se conoce solo parcialmente en el extremo que apoya en la fachada de la domus con la que forma ángulo recto, ya que estructuras posteriores destruyeron el resto de la edificación. En su construcción se aprecia el uso de adobes de dos módulos distintos, de $28 \mathrm{~cm}$ de lado por $8 \mathrm{~cm}$ de grosor en el lateral derecho de la estructura y de $36 \mathrm{~cm}$ por $8 \mathrm{~cm}$ de grosor en su lateral izquierdo. En el exterior de la esquina formada por los dos muros se ha documentado una pieza de piedra de forma circular, con paredes rectas y el fondo plano, que aparece in situ, encajada en el suelo. Se trata de una meta de un molino de tipo pompeyano que aparece reutilizada, volteada y vaciada para ser utilizada como contenedor.

El horno, también documentado parcialmente, se adosa al muro de tapia. Se ha conservado la base, así como una parte poco representativa de la bóveda, formada por adobes de forma trapezoidal, y de la parrilla maciza, de la que solo restan algunos fragmentos de los ladrillos en la zona del arranque de la bóveda (fig. 3 y 4). En función de los restos aún visibles, se puede hablar de una estructura circular con un diámetro $c$ 2,5 metros. Al no conservar su totalidad es difícil determinar la zona de acceso o la existencia de elementos auxiliares. No obstante la forma del muro asociado y la disposición de los adobes supervivientes podrían apuntar a un acceso al horno desde la zona conservada. Otro punto a tener en cuenta es la 


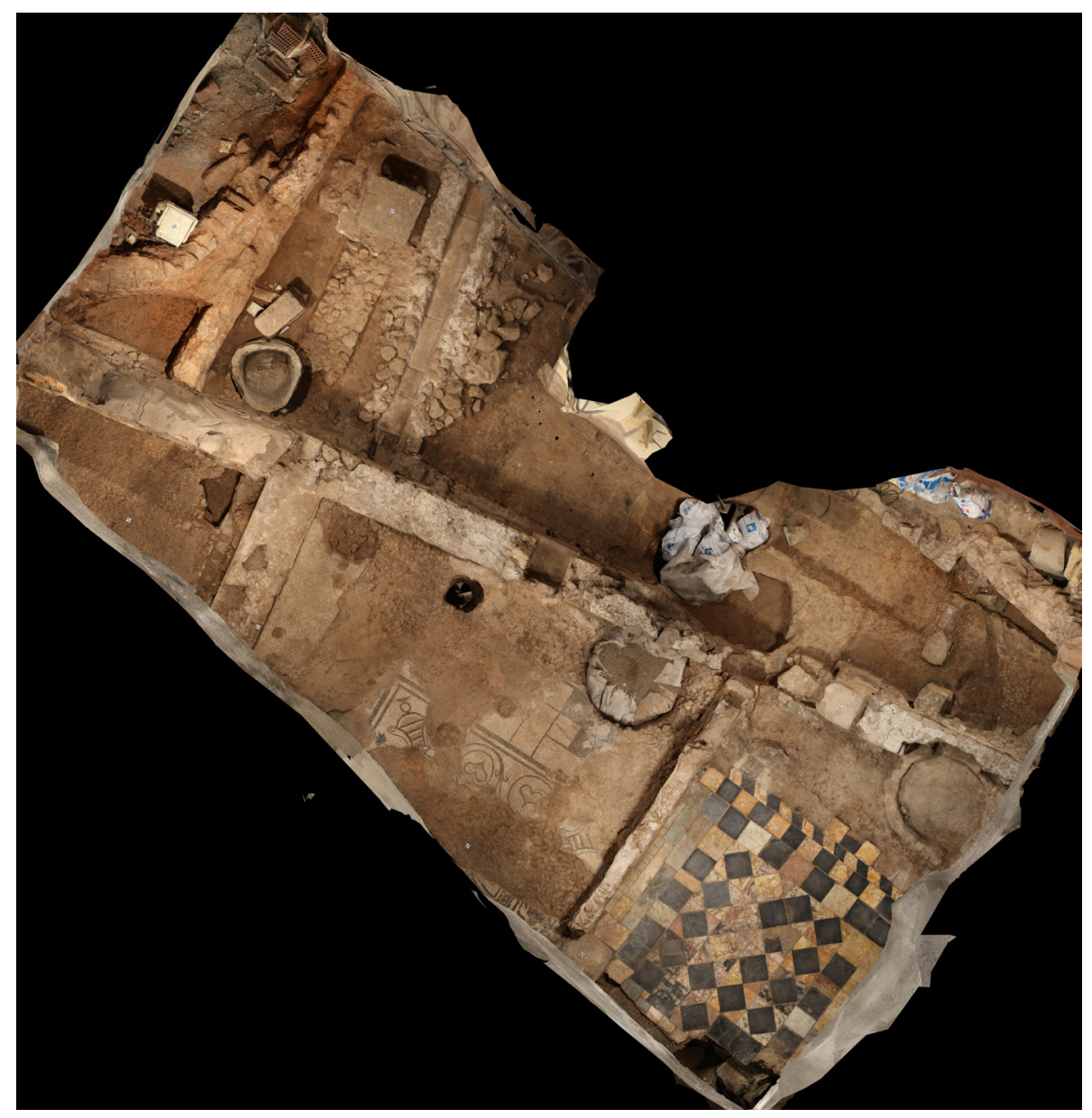

Figura 2. Ortofoto de los restos documentados en la calle Avinyó, 15.

situación del molino reutilizado como contenedor, un elemento que aparece situado habitualmente junto a la boca del horno, como apreciamos en las panaderías de Pompeya.

De esta forma nos encontraríamos con un horno de calentamiento directo de forma cuadrangular, de estructura interna circular con cubierta cupulada. Se trata de una tipología bien conocida en los pistrina del Imperio, dotados de este tipo de hornos de gran tamaño, como conocemos especialmente bien para el caso de las ciudades de Pompeya y Herculano gracias a los trabajos desarrollados por N. Monteix. En el caso hispano, los recientes trabajos de M. Bustamente y J. Salido han permitido incrementar notablemente nuestro conocimiento sobre estos centros de producción, aunque todavía son escasos los ejemplos peninsulares documentados (Bustamante, Salido y Gijón 2014; Salido y Bustamante 2014). Destacan los hornos de la Casa del Planetario y el horno de la Casa de los Pájaros de Itálica, junto con el horno de la calle Almendralejo de Mérida, ya que son similares en técnica constructiva a nuestra estructura de combustión.

Es significativa también la presencia de una meta reutilizada, dispuesta en la fachada del horno, flanqueando el acceso a la cámara de calor (fig. 5). La presencia de este tipo de elementos reutilizados como contenedores es tremendamente habitual en las panaderías, siendo utilizados con diversas funcionalidades, como han puesto de manifiesto los estudios realizados en los últimos años por N. Monteix sobre los pistrina de Pompeya (Monteix 2009 y 2010 y Monteix et al. 2011, 2012, 2013 y 2014)

En nuestro caso, la localización de la pieza implica su uso bien como un pequeño depósito destinado a contener agua, que era así caldeada para su uso en la elaboración de la masa, bien como un cenicero vinculado a la limpieza del horno. La utilización de pequeños depósitos destinados a caldear agua, localizados en la frontal del horno, que reutilizan durmientes de molino está atestiguado en la panadería IX 3, 19-20 de Pompeya, en 


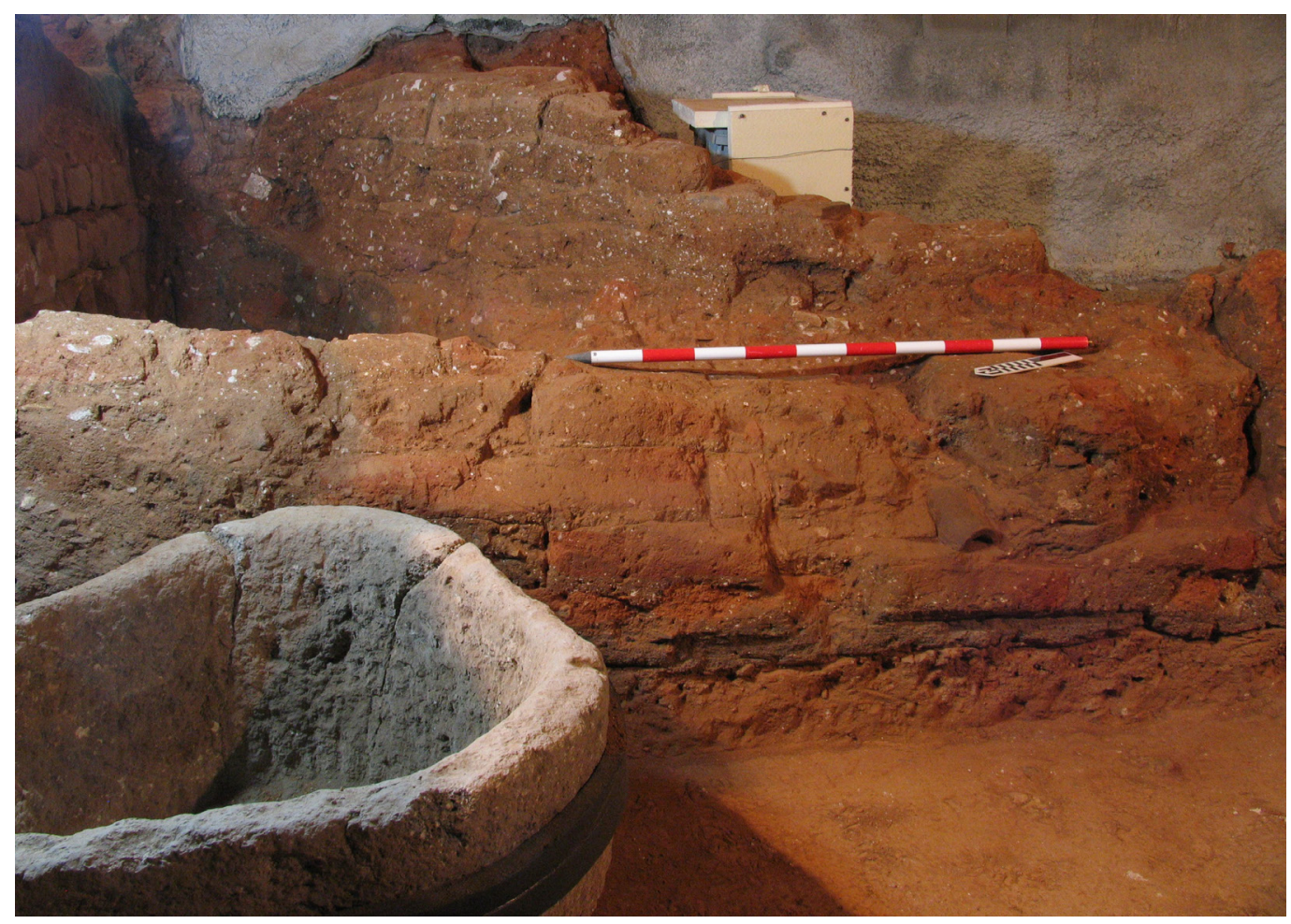

Figura 3. Detalle de los adobes que conforman el horno.

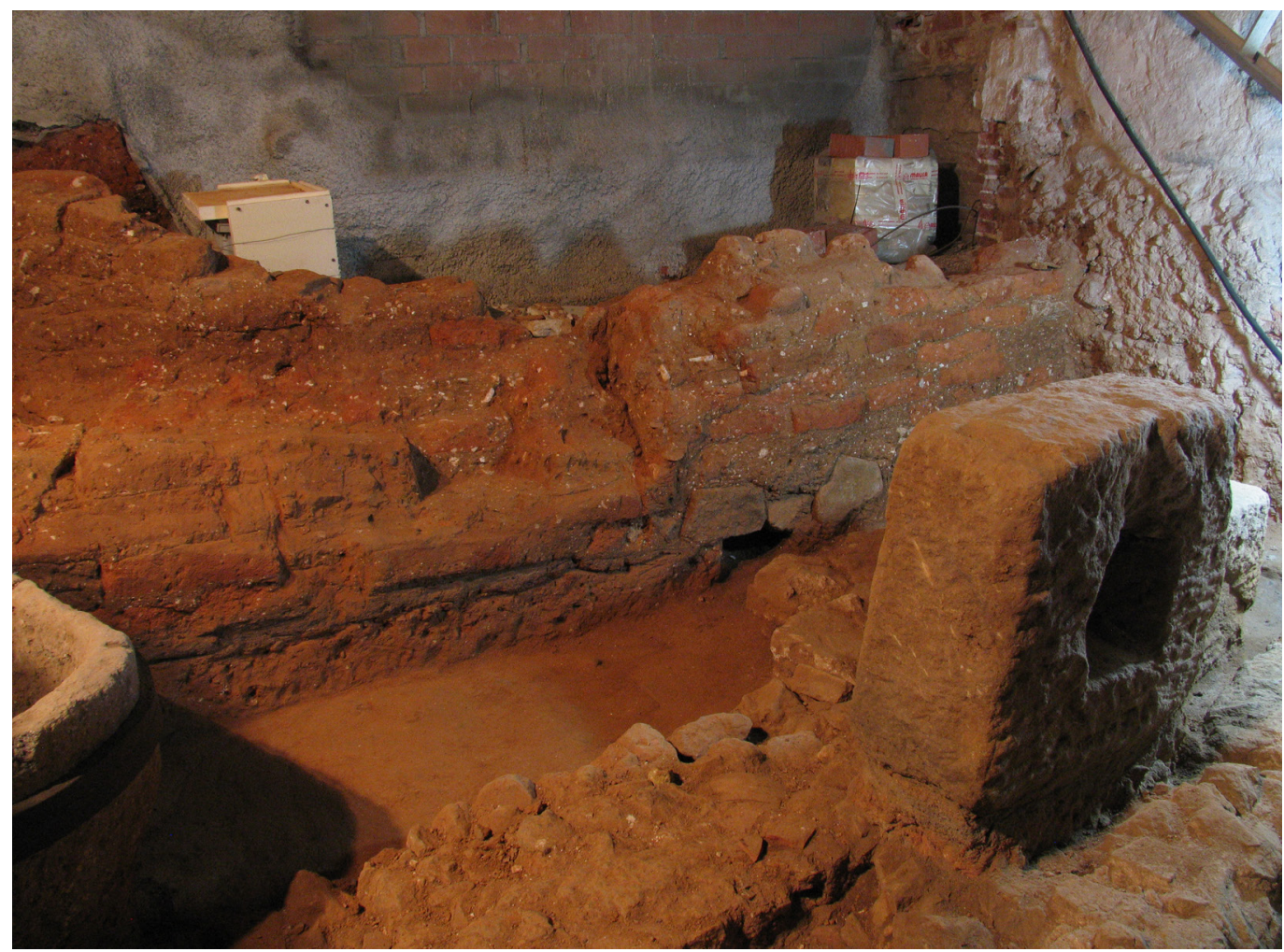

Figura 4. Vista del muro del cierre y de la cámara de cocción del horno.

ISSN: 1133-4525 ISSN-e: 2255-3924 


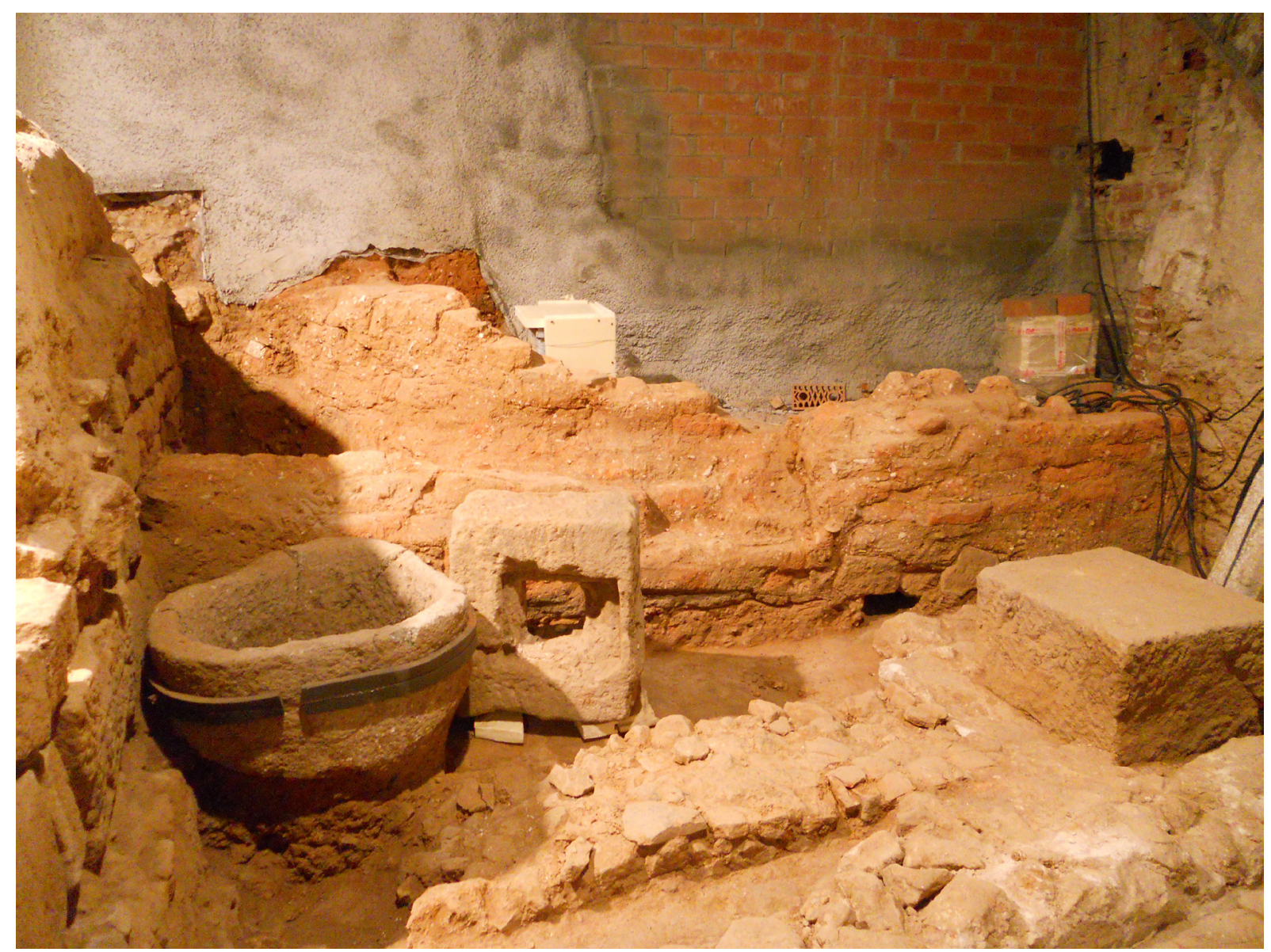

Figura 5. Horno y molino volteado reutilizado como contenedor.

la que se aprecia su uso como pila de fuente con desagüe, y en la panadería de los Castos Amantes, en este caso sin orificio de salida. También se constata la aparición de pequeños recipientes destinados a este uso en los hornos de la panadería VI 14, 33-34 de Pompeya, con un elemento de forma también circular y realizado en piedra, y en la panadería VIII 6, 1.9-11, también de esta misma ciudad, en este caso utilizando el fondo de un ánfora oleícola Dr. 20. El uso de estos elementos reutilizados como ceniceros, dispuestos también en la fachada del horno, se atestigua en las dos metas volteadas situadas a la derecha de la boca del horno de la panadería de los Castos Amantes (fig. 6) y en la panadería IX $12,6-8$, en la que una meta es también reutilizada con esta función. En el caso de las panaderías VI 11, 9-10 y VII 1, 36-37 se constata la presencia de durmientes volteados reutilizados, dispuestos en la fachada del horno sin que, como en el caso de Avinyó, podamos determinar su funcionalidad específica.
Respecto al molino, este tuvo que ser extraído de su posición original para ser consolidado antes de poder documentar su forma íntegra. Esta pieza (fig. 7) presenta una forma troncocónica, vaciado su interior creando unas paredes rectas que varían de grosor en función de la zona. El grueso de estas paredes oscila entre los 4 y los $14 \mathrm{~cm}$, configurando un espacio interno de $60 \mathrm{~cm}$ de diámetro por $33 \mathrm{~cm}$ de profundidad, lo que arroja una capacidad de $c 93$ litros. En la parte interior se pueden ver las marcas del pico utilizado para su vaciado, mientras que la exterior presenta la textura característica de este tipo de piezas, no estriadas y con las zonas de contacto tremendamente alisadas por el desgaste. El uso hizo que la superficie de molido hubiera perdido gran parte del grosor, hecho que propició su agrietado y la pérdida de parte de la pieza, obligando a su inutilización y su reutilización como contenedor, en un proceso bien conocido en los pistrina romanos, como hemos visto. 


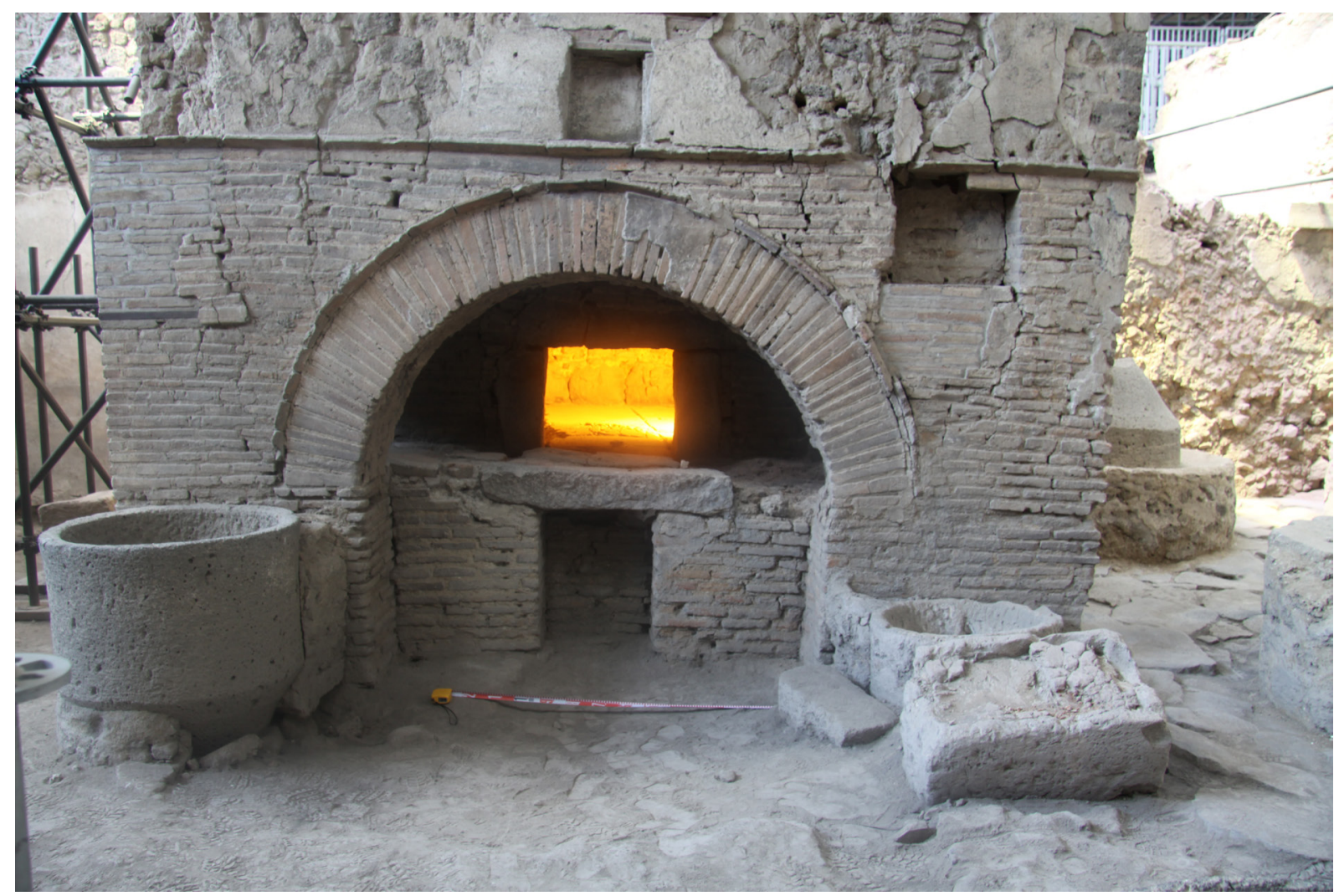

Figura 6. Horno de la panadería de los Castos Amantes (Pompeya).

Por sus características se identifica con claridad como una meta, o durmiente, de un molino pompeyano de tracción animal, que según la tipología de S. Longepierre incluiríamos en el tipo 451d, variante XXIX, que presenta una amplia cronología de uso a partir del siglo I a.C. y hasta el s. V d.C. (Longepierre 2012: 89). La tipología de los molinos harineros, realizada inicialmente por D. Peacock (Peacock 1989) ha sido recientemente revisada y ampliada, a propósito de un intenso estudio centrado en la Galia, por este investigador (Longepierre 2012). Para el caso de Hispania el estudio de los molinos se encuentra aún muy retrasado respecto de otras zonas del Imperio, haciéndose imprescindible una catalogación y estudio de los numerosísimos artefactos documentados. Cabe mencionar el reciente estudio de T. J. Anderson sobre las moleras del sur de la península ibérica (Anderson 2014 y 2016). Para una síntesis sobre el estado de la investigación en el Mediterráneo occidental de los elementos de molienda, remitimos al prólogo realizado por J.P. Brun para la obra Pistrina Hispaniae (en Salido y Bustamante 2014: 5-7).

Los estudios pétreos realizados sobre la pieza (Gimeno et al. 2010) permiten, además, situar su origen en canteras cercanas a la ciudad italiana de Orvieto, en Etruria, lugar de larga tradición en la elaboración de este tipo de piezas. Los molinos de estas canteras de piedra volcánica son bien conocidos, así como su comercio esencialmente en el occidente mediterráneo, también con unas cronologías muy amplias. Estos molinos fueron originalmente estudiados por D.P.S. Peacock, a partir del estudio de las panaderias pompeyanas (Peacock 1980, 1986 y 1989). A partir de estos estudios comienzaron a intensificarse los análisis geológicos de los elementos de molienda y sus rutas comerciales (Williams-Thorpe 1988 y Buffone et al. 1999). En los últimos años, un grupo de investigadores encabezados por A. Chartrain y M. Gualtieri ha puesto en funcionamiento un proyecto de investigación centrado en los molinos manufacturados en Orvieto, atendiendo tanto al estudio de sus canteras como a la distribución y comercialización de estos artefactos, realizados ya desde época etrusca ((http://www.orviamm.com/ y Chartrain 2015 y Gualtieri 2015).

En relación con el carácter artesanal o doméstico del horno, creemos que contamos con argumentos suficientes para interpretar estas estructuras como 


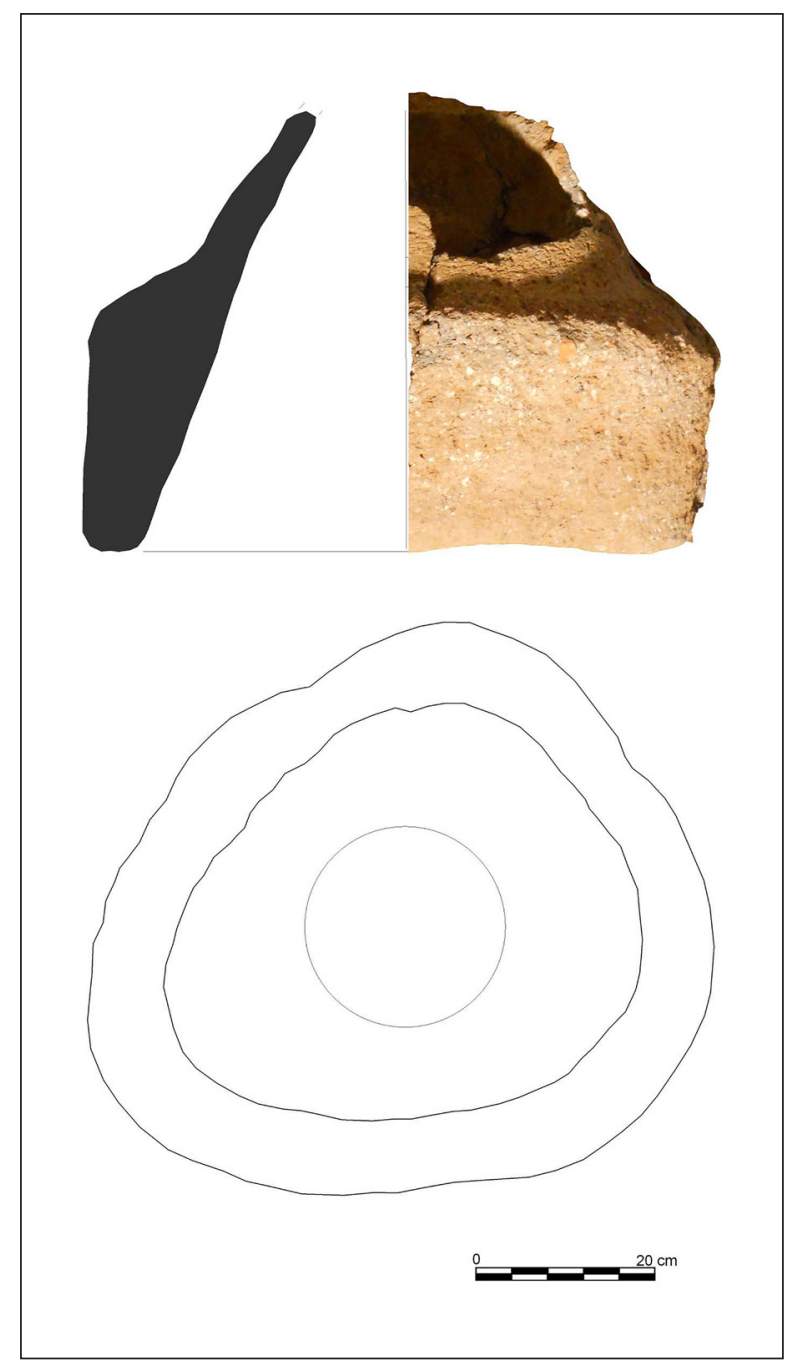

Figura 7. Dibujo de planta y sección del molino harinero.

pertenecientes a un pistrinum urbano. Tanto el tamaño del horno como el tipo de molino, pompeyano y de tracción animal, indican que estamos ante un ámbito artesanal que supera las necesidades productivas domésticas. También constatamos la falta de conexión entre las estancias domésticas y de representación de la domus y el espacio que ocupa nuestra instalación, ubicado sobre el antiguo intervallum de la ciudad y, como hipótesis, con acceso directo a la calle desde el cardo que limita la insula en su lateral occidental. La falta de vinculación entre las estructuras productivas y la domus no puede ser garantizada por completo debido a que puede existir una zona de conexión entre ambas fuera del espacio intervenido.

Respecto al área de trabajo total ocupada por este taller, consideramos la existencia de tres posibles límites claros, como serían la propia fachada de la $d o-$ mus, el horno y la anchura del intervallum, de alrededor de $6 \mathrm{~m}$. La cuarta, es decir, la distancia al cardo más cercano solo se puede aproximar, teniendo en cuenta que nos encontramos en una insula irregular por situarse en uno de los quiebros de la muralla (fig. 8). Según la interpretación realizada de la forma de esta insula y su situación, se puede determinar una longitud de unos 16 metros. Estas aproximaciones determinarían una extensión para nuestro enclave productivo de en torno a los $100 \mathrm{~m}^{2}$, situándose el horno posiblemente, como suele ser habitual, en la parte posterior de la panadería. La zona anterior quedaría destinada a alojar los molinos, los espacios destinados al amasado-fermentación de la masa y la elaboración de las piezas a hornear, así como el posible despacho de pan abierto a la calle. Tampoco podemos descartar la presencia de cuadras, ubicadas en este espacio artesanal, destinadas a alojar las acémilas encargadas de hacer funcionar los molinos.

Cabe señalar también en el caso de Barcino, la aparición de diferentes evidencias indirectas de la presencia de otras panaderías en el interior de la ciudad. En el caso de la ciudad de Pompeya, salvando todas la distancias cronológicas, sociales y geopolíticas, se han localizado 36 panaderías en una ciudad de 66 hectáreas de extensión; Barcino, con una extensión de 10 hectáreas, podría haber albergado, según estos cálculos, entre cinco y seis de estos enclaves artesanales.

En el caso de Barcino constatamos el hallazgo de fragmentos de molinos harineros en diversos espacios intramoenia. Dos de estos molinos provienen con certeza, también, de la zona de de Orvieto (Gimeno et al. 2010). El primero de estos fragmentos se localiza en el relleno de la muralla tardorromana, en la zona de la actual Plaza del Rei. Se trata de un fragmento de $c 20 \mathrm{~cm}$ que no ha podido ser dibujado y estudiado morfológicamente debido a que permanece formando parte de la obra de la muralla. El segundo fragmento se ha localizado formando parte de un muro datado en el siglo VI d.C. de la domus de Sant Honorat (Florensa 2011). También se conoce la existencia de otro molino en la zona ocupada por la factoría de salazones, en el subsuelo arqueológico del Museo de Historia de Barcelona (Muhba). Se trata de una pieza con unas características similares al recuperado en Avinyó, incluso aparece reutilizado como un contenedor. Aunque no ha sido analizado, su observación macroscópica parece indicar que procede también de estas canteras itálicas. 


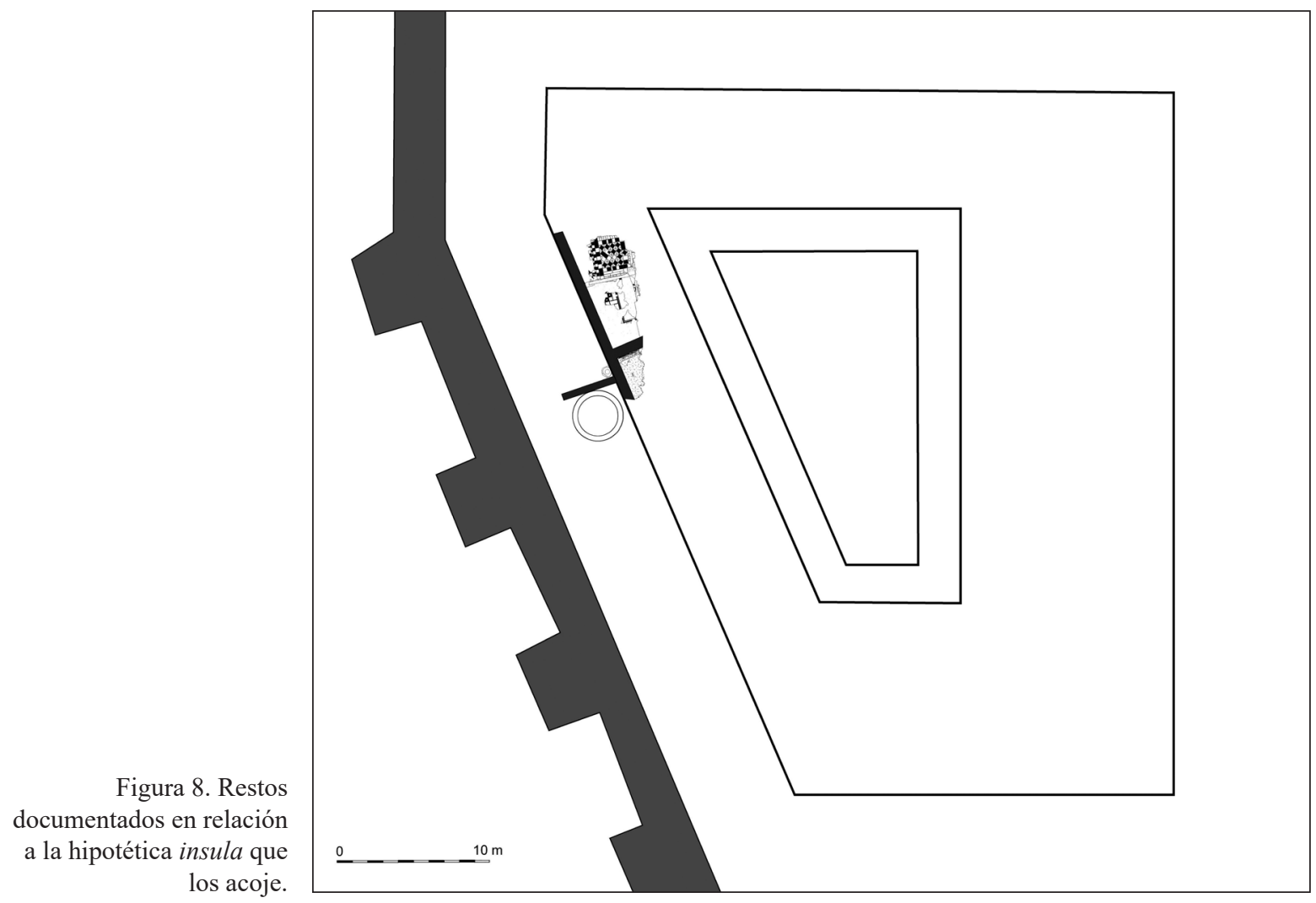

\section{EL ARTESANADO TARDORROMANO EN BARCINO}

A finales del s. III o principios del s. IV d.C. detectamos en la ciudad de Barcino una intensa actividad constructiva tanto desde el punto de vista público, como desde el punto de vista de la edilicia privada, con importantes reformas de carácter suntuario en prácticamente todas las domus conocidas de la ciudad (Cortés 2011; Perich 2014; Beltrán 2010, 2013 y 2014).

Una de las primeras reformas a nivel urbano fue la construcción en la segunda mitad del siglo III del segundo recinto defensivo, con 4 puertas y 76 torres de formas y medidas diversas (Balil 1961; Puig y Rodà 2010; Ravotto 2014; Ramos 2015 y Miró 2015). Estas reformas incluyen también el nacimiento de talleres urbanos artesanales, como hemos visto en el apartado precedente, vinculados o no a espacios residenciales (fig. 9). Se configuran en este momento dos grandes sectores artesanales en el interior de la ciudad, que aglutinan, como veremos, espacios productivos de distinta naturaleza. Frente a este incremento de los espacios productivos intramuros, asistimos a la práctica desaparición de la actividad industrial en los suburbia de la ciudad, que coincide con la construcción de nuevos espacios de producción agropecuaria en las villae situadas en el ager de Barcino.

Intramuros destaca, desde el punto de vista de la actividad artesanal, la intensa reforma llevada a cabo sobre la domus altoimperial de la Plaza de Sant Miquel, que supone el cierre parcial de uno de los decumani de la ciudad. Este fenómeno de apropiación de los espacios públicos, bien conocido ya para época tardía y que en el caso de Barcino arranca con una temprana ocupación del intervallum desde el s. I d.C., se materializa también en la construcción de la bodega de la Plaza del Rei y, como hemos visto, en la construcción de la panadería de la Calle Avinyó, ambas también en el espacio perimetral interior de la muralla. A esta actividad edilicia hay que añadir la construcción, en la domus de Sant Felip Neri, de un espacio de prensado vinculado a la elaboración de vino o aceite. Desde el punto de vista comercial, a principios del s. IV d.C. también se produce la construcción de las nuevas tabernae de la domus de Sant Honorat (Florensa 2011).

Una de las remodelaciones urbanísticas más importantes documentadas para época tardorromana en la ciudad de Barcino se concentra, como decíamos, 


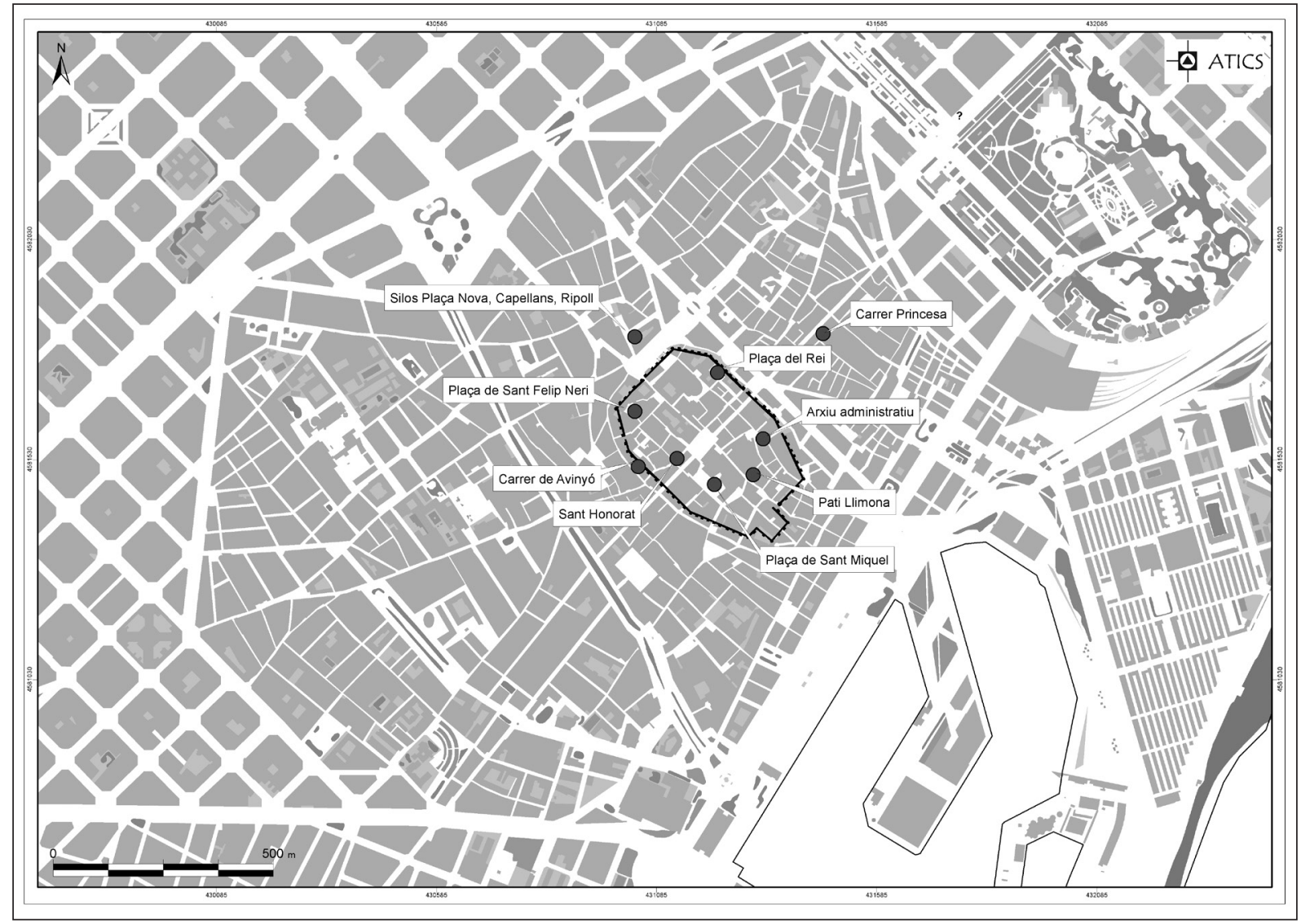

Figura 9. Plano con relación de enclaves urbanos y suburbanos citados en el texto.

en el entorno de la llamada domus de la Plaza de Sant Miquel. En esta zona, entre los años 1960 y 1962, se llevan a cabo una serie de obras encaminadas a la construcción de nuevas dependencias municipales, que serán realizadas con control arqueológico bajo la dirección de Josep de Calasanç Serra i Rafols. Una parte de los restos es destruido sin control arqueológico y en muchos casos se realiza tan sólo un seguimiento de las obras con recuperación de los elementos arqueológicos más destacados. Contamos, sin embargo, con una memoria inédita firmada por Magí Travesset i Queraltó, que nos permite una cierta aproximación a los restos exhumados (Travesset 1960-1961).

De esta forma, este seguimiento arqueológico permite documentar los restos de diversos edificios de carácter industrial, fechados a principios del s. IV d.C., que implican una remodelación del tejido urbano, $\mathrm{y}$ posteriormente, en el año 1989 nuevas excavaciones documentan una domus de peristilo en el ángulo sureste del área intervenida. La reforma supone la anulación parcial de uno de los ejes viarios con dirección
E-O, que pasaría a convertirse ahora en una calle sin salida con acceso desde su extremo occidental, coincidiendo con el cardo fosilizado en la actual calle de Templers. En torno a este eje viario, cerrado ahora con la construcción de un edificio en su extremo occidental, se localizan una serie indeterminada de construcciones dotadas de piletas, desagües y pavimentos de opus signinum con media caña, que permiten su interpretación de forma genérica como espacios artesanales (fig. 10). El problema para la interpretación funcional específica de estos espacios deriva de la falta de datos disponibles, apenas contamos con documentación fotográfica y con una breve descripción de los restos documentados, sosteniéndose nuestro conocimiento de la zona casi exclusivamente en la planimetría realizada.

De esta forma, se detectan un máximo de ocho espacios, de los cuales dos de ellos tendrían acceso desde el cardo occidental, que seguiría la dirección de la actual calle de la Font de Sant Miquel. Estamos hablando de los edificios señalados en los planos como 1 y 3 , aunque no podemos descartar que se trate de un único complejo 
productivo, debido a que conocemos tan solo parcialmente su planta. El llamado Edificio 1 ciega con su construcción el decumano que articula el complejo y al que hemos hecho antes mención. Se trata de un edificio formado aparentemente por tres estancias, pavimentadas con opus signinum, en las que destaca la presencia de un depósito en obra en la sala central. Esta cubeta tiene unas dimensiones de 2,20 $\mathrm{m}$ por 3,30 $\mathrm{m}$, con profundidad desconocida y presenta revestimiento de opus signinum, cuarto de bocel y pocillo de limpieza en su fondo. Se constata también un desagüe de salida en su parte inferior, que aparece conectado con una canalización subterránea que recorre el decumano con dirección este, para encontrarse con la cloaca del cardo de la calle Templers. La estancia que acoge esta cubeta presenta una cota de circulación situada $60 \mathrm{~cm}$ por encima del resto de niveles de uso del edificio, lo que podría interpretarse como una solución constructiva para maximizar el funcionamiento de una prensa de viga. La compartimentación a diversa cota es un elemento clave en la construcción de salas destinadas a albergar prensas de viga, debido a que permite desarrollar un mayor y menos costoso desplazamiento vertical de estos sistemas de prensado (Brun 2004: 13-15 y Peña 2010: 47-48).

Según esta hipótesis la zona de prensado se situaría en la sala central, mientras el mecanismo de accionamiento de la prensa se localizaría en la estancia situada al sur, con una cota más baja de circulación y con tres escalones de acceso para salvar el desnivel y permitir acceder a la zona sobreelevada. La presencia de un desagüe inferior en el depósito, conectado con un canal de salida, es poco habitual en las instalaciones de prensado y cuando aparece, lo hace exclusivamente en el caso de la elaboración de aceite, vinculado con la salida del alpechín tras completar la decantación. Recientemente se han identificado en la Península Ibérica sistemas de decantación, tanto manuales como mecánicos, de decantación por trasvase del alpechín. A la vista de los hallazgos documentados debió tratarse de un sistema ampliamente usado en las almazaras hispanas (Peña 2011-2012: 50).

A pesar de que la hipótesis es sugerente, la parcialidad de los datos disponibles nos impide afirmar con rotundidad la presencia de una industria destinada a la extracción de aceite.

Respecto a la posibilidad de contemplar este taller como una instalación de prensado oleícola, cabe realizar otra observación debido a su vinculación topográfica con las termas públicas de la plaza de Sant Miquel (Pallares 1969 y Miró-Puig 2000), que se localizan en la misma calle en la manzana inmediatamente superior. La

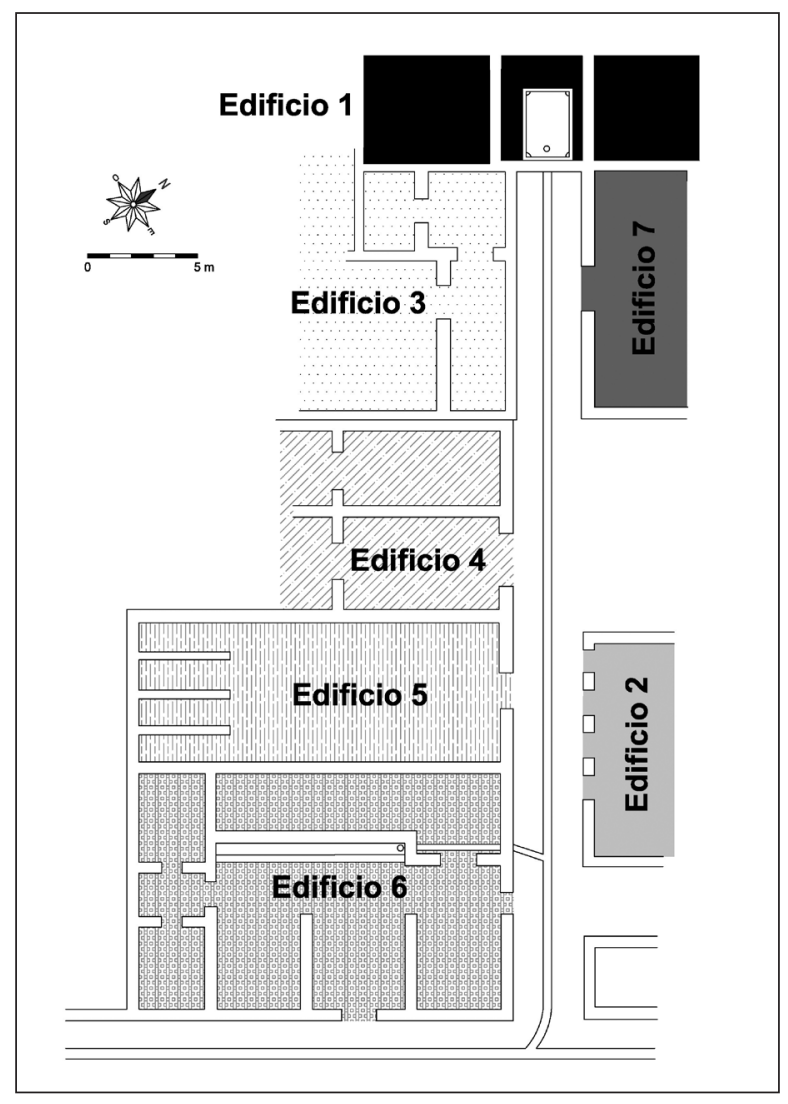

Figura 10. Planta de los restos documentados en la intervención realizada por Serra i Rafols en la Plaza de Sant Miquel.

presencia de perfumerías en las zonas centrales de las ciudades en conexión con los espacios cercanos a los establecimientos balnearios es bien conocida gracias a los trabajos de J.P. Brun (Brun 2000; Brun y Monteix 2009). Si consideramos la posibilidad de interpretar el Edificio 1 del conglomerado artesanal de Sant Miquel como destinado a la elaboración de aceite, su conexión con la elaboración de perfume parece más que plausible.

También debe tener su acceso desde el cardo localizado en la actual calle de la Font de Sant Miquel el edificio señalado con el número 3 por Serra Rafols. De este edificio conocemos tan sólo cuatro estancias, pavimentadas con opus signinum, que carecen de elementos estructurales que nos permitan concluir su posible funcionalidad. Cabe la posibilidad incluso de que este espacio productivo pudiera haber estado conectado con el Edificio 1.

Justo en el extremo opuesto de la insula, al sur de las dependencias residenciales de la domus de Sant Miquel, y ocupando la esquina formada por la unión de los viales antiguos que siguen la dirección de las actuales 
calles de Gegants y Templers, se localizan una serie de estancias dispuestas en batería que han sido erróneamente interpretadas como tabernae, ya que no aparecen abiertas a los viales. Se han localizado hasta cinco estancias, pavimentadas en todos los casos con opus signinum, que debemos vincular a un posible uso productivo indeterminado debido a la falta de elementos identificativos. El acceso a este complejo debió realizarse bien desde la propia zona residencial de la domus, bien desde un acceso localizado en el decumano de la actual calle Gegants.

Continuando con la línea de fachada que marca el eje vial N-S de la calle Templers, nos encontramos con una nueva edificación (Edificio 6), pavimentada por completo con opus signinum, que presenta acceso desde la propia calle Templers y desde el decumano sin salida. Este edificio presenta una organización tripartita con tres estancias simétricas dispuestas en batería, dos de las cuales albergan los accesos al complejo, dos estancias menores conectadas gracias a un distribuidor, con una funcionalidad aparente de almacén, y un espacio de trabajo alargado y abierto dispuesto en el lateral oeste. En esta zona se detecta un desagüe que conecta con una canalización de salida, la cual vierte en el ramal de cloaca localizado en el decumano, que provenía como hemos visto del edificio 1 y enlaza con la cloaca del cardo de la calle Templers. La presencia de este desagüe indica un uso intenso de líquidos en la industria desarrollada en este espacio productivo, que carece sin embargo de depósitos en obra, por lo que podemos descartar, en principio, que estuviera destinada a la elaboración de salazones de pescado, trabajos textiles o elaboración de vino o aceite.

Al oeste de este edificio, con acceso desde el vial sin salida, se localiza el llamado Edificio 5, un espacio productivo dotado de una única habitación en la que destaca la presencia de tres muros paralelos con una longitud de 4,2 m, que debieron actuar como soporte de un suelo sobreelevado de madera, que delimita un espacio de $27,9 \mathrm{~m}^{2}$, situado al fondo del ambiente productivo. La aplicación de este tipo de solución arquitectónica aparece vinculada tradicionalmente al almacenamiento de rendimientos agrarios, sin que podamos determinar la funcionalidad específica del ámbito que lo acoge. Esta estructura ha sido previamente interpretada por J. Beltrán de Heredia como una estructura destinada a sostener un mostrador de madera destinado al despiece del pescado (Beltrán 2013: 21-22). La gran extensión de la superficie sobreelevada, más de $25 \mathrm{~m}^{2}$ y la ausencia de elementos imprescindibles en las industrias salazoneras, como depósitos o elementos hidráulicos que permitan el lavado del pescado, nos llevan a considerarlo como un espacio de almacenamiento sobreelevado con los mismos principios constructivos documentados en los horrea (Salido 2011).

Siguiendo hacia el oeste, encontramos un nuevo edifico productivo, marcado con el número cuatro, $\mathrm{y}$ con un vano de acceso de 1,7 m, abierto también al lateral meridional del decumano. En este caso el acceso al edificio viene marcado por un espacio a cielo abierto como parece deducirse de su pavimentación, realizada con losas de piedra irregulares muy erosionadas. Desde este espacio se accede a un segundo ámbito, pavimentado ya con opus signinum, que da paso a su vez a un tercer espacio que comunica con una cuarta sala, ambas con pavimento hidráulico. Nuevamente la falta de elementos estructurales indicativos nos impiden determinar la funcionalidad de este edificio, en el que el ámbito de entrada podría funcionar como un espacio destinado a la carga para el posterior transporte del producto elaborado, no detectándose así con claridad una actividad comercial directa. Al lateral norte de esta calle sin salida de la que venimos hablando, se abren otros dos edificios (Edificio 2 y Edificio 7), conocidos muy parcialmente, y de los que no podemos determinar con certeza su vinculación a actividades artesanales.

Como vemos, asistimos en época tardorromana a una reordenación del tejido urbano, que incluye la modificación parcial del trazado viario, destinada a crear un barrio artesanal en el corazón del espacio urbano. Otra aglomeración similar de ámbitos productivos se localiza en el ángulo noreste de la ciudad en el espacio comprendido entre el foro y la muralla, bajo la actual Plaza del Rei, muy cerca de la llamada Puerta Septentrional. Estas estructuras productivas son excavadas inicialmente por A. Duran i Sampere en 1931, continuándose su excavación en 1952-1953 bajo el salón del Tinell. Las obras realizadas en 1998, enfocadas a la remodelación de esta área arqueológica destinada a su musealización, por parte del equipo del Museo de Historia de Barcelona (Muhba) dirigido por J. Beltrán de Heredia, permitieron interpretar estas estructuras como pertenecientes a un barrio artesanal (Beltrán de Heredia 2001a, 2001b y 2001c). De esta forma se han localizado los restos de una fullonica, una tinctoria, una cetaria y una bodega, en funcionamiento en los dos primeros casos a partir de la segunda mitad del s. II d.C., mientras la instalación de salazón comienza a funcionar en el s. III d.C. y la bodega posiblemente ya a principios del s. IV d.C. Respecto a la vinculación de esta zona artesanal/comercial con unidades residenciales, en el caso de la fullonica y la tinctoria parece claro que se trata de enclaves 
productivos independientes. En el caso de la cetaria y el torcularium vinícola, ambos integrados en la misma insula que la domus documentada bajo la plaza de Sant Iu, J. Beltrán de Heredia (Beltrán de Heredia 2005: 283) vincula ambas industrias con esta domus, mientras A. Cortés defiende que la falta de conexión topográfica entre ambas impide precisar si los espacios productivos pertenecen o no la construcción doméstica (Cortés 2011: 26). Hay que señalar, también, la presencia de un espacio comercial en la intersección del intervallum con el cardo minor que separa las dos manzanas que acogen este núcleo productivo de la ciudad.

Como hemos visto, la construcción de espacios industriales en esta zona se remonta, al menos, a la segunda mitad del s. II d.C., con la construcción de una fullonica y una tinctoria, y se mantiene como barrio artesanal a lo largo de los s. III y IV d.C. Estos dos primeros complejos artesanales se sitúan en el extremo noroeste de la insula ubicada en el lateral norte del foro y aparecen abiertos al intervallum de la ciudad, aunque sin conexión y con accesos independientes desde el exterior. De la fullonica se han conservado tan sólo cuatro estancias, no habiéndose localizado los típicos saltus fullonici, en los que los operarios lavan la ropa mediante el pisado. Se ha localizado una sala con una pequeña cubeta de aclarado, con residuos de orina y ceniza, característicos detergentes en el mundo romano, así como una sala destinada al aclarado de la ropa, dotada de una gran pileta (lacuna fullonica), y dos estancias más de funcionalidad indeterminada. Destaca el hallazgo de una sala pavimentada con opus signinum y con un emblema central de opus sectile, que se interpreta como un espacio de recepción de clientes o destinado a la administración del negocio.

Por su parte la tinctoria, situada inmediatamente al oeste de la instalación anterior, presenta un acceso desde el exterior que da acceso directo a un pasillo que comunica con una gran sala, situada en la parte trasera, pavimentada con opus signinum en la que se han documentado tres piletas destinadas a acoger los tintes. El número de tanques de teñido pudo ser más numeroso, ya que una parte de la sala aparece completamente desmontada por la construcción de una piscina de época tardía. Se detecta una caja de escalera y una serie de estancias pavimentadas con opus signinum que tanto podrían vincularse con esta instalación como constituir espacios comerciales abiertos al intervallum o al cardo minor.

En el interior de esta instalación se han documentado un buen número de herramientas destinadas al trabajo textil, que podrían indicar la presencia de telares en la propia instalación tintorera. Podríamos estar, por tanto, ante un centro de producción textil, que aglutinara también las labores de tintado de las prendas manufacturas. En este sentido, cabe señalar la intensa actividad de fabricación de pondera constatada en la excavación del alfar de la calle Princesa (Casas y Martínez, 2006; Casas 2009), que muestra de forma indirecta la importancia que la industria textil debió alcanzar ya en el Barcelona desde época romana.

También en el espacio próximo a la muralla, pero en este caso en la insula situada al oeste y con una cronología posterior, se localiza un espacio de transformación de pescado y una bodega, sin que en ese momento podamos, como hemos señalado con anterioridad, precisar si estos espacios están vinculados o no a la domus localizada en esta misma manzana bajo la plaza de Sant Iu. La instalación destinada a la elaboración de salazones se encuentra en funcionamiento desde el s. III d.C. y presenta un acceso desde un cardo minor porticado. El complejo industrial se articula en torno a un patio, pavimentado con losas de piedra y opus signinum, en el que se localizan una serie de cubetas de distinto tamaño destinadas a la maceración del pescado. Abiertas a este patio se localizan dos estancias con dolia ovoides, utilizados aparentemente también como recipientes destinados a la salazón del pescado. Uno de estos dolia se sitúa directamente sobre el pórtico de la calle, que en este momento es compartimentado, quedando una parte de este espacio público integrado en la instalación conservera.

Por su parte, la instalación de prensado se sitúa en el ángulo norte de la insula, abierta al cardo minor y rebasando sus límites, ya que parte de la instalación invade el intervallum adosándose directamente sobre la muralla augustea. No se conoce la planta completa de este torcularium urbano, ya que sus estructuras se verán profundamente afectadas por edificaciones posteriores, sobre todo en su sector sudeste. De igual modo, la reconstrucción de su evolución temporal es prácticamente imposible de realizar, debido a la falta de estratigrafía. Sin embargo, tenemos un término post quem claro en las ánforas enterradas en la cella vinaria, que se fechan en la segunda mitad del siglo III d.C. También sabemos que en el siglo VI d.C. se construye una iglesia en este solar y que en algún momento del siglo IV o $\mathrm{V}$ d.C., la domus entera parece ser cedida al obispado de Barcelona (Bonnet y Beltrán de Heredia 2001; Beltrán de Heredia 2013: 30-34). Podemos imaginar que la producción de vino continuaría, hasta una fecha indeterminada, bajo el control de la Iglesia (Peña 2008). La falta de estratigrafía, debida a la excavación antigua de esta zona, y la gran acumulación de edificaciones anteriores 

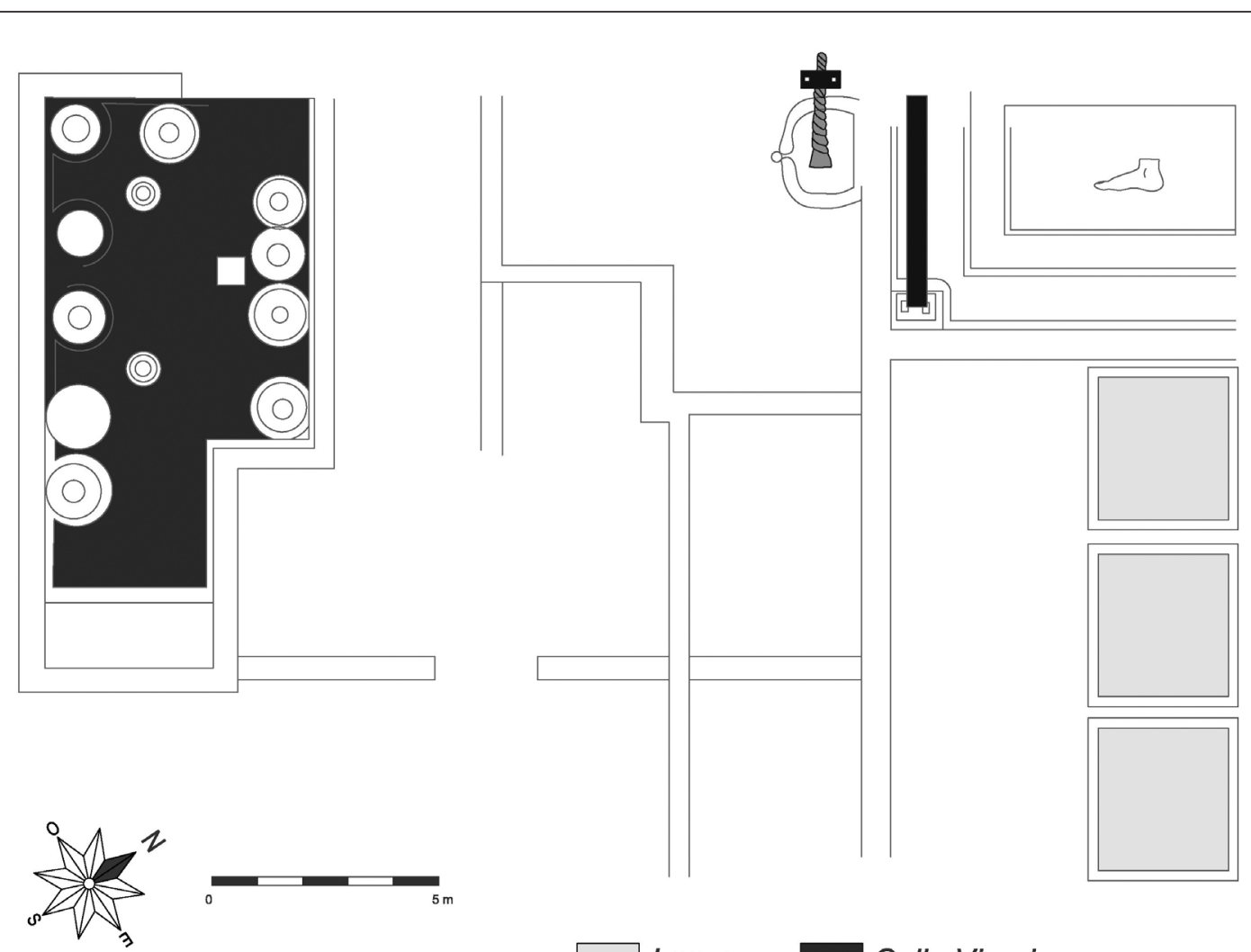

Lacus

Cella Vinaria

Figura 11. Hipótesis de funcionamiento de la bodega de la Plaza del Rei.

y posteriores dificultan la interpretación funcional del complejo. La revisión de los datos disponibles para el análisis tecnológico de este torcularium vinícola nos permite lanzar una nueva hipótesis de interpretación (fig. 11), que modifica parcialmente las propuestas funcionales realizadas con anterioridad (Beltrán de Heredia 2001c y 2009), alguna de ellas creemos que hoy superada (Peña 2010: 356-361)

La zona de estrujado, junto a los lacus de recepción, se sitúa adosada a la muralla, ocupando el espacio del antiguo intervalllum. Aquí se documenta el lugar destinado al prensado, con un sitio definido para la pisa gracias a un zócalo revestido de opus signinum, con presencia tanto al interior como al exterior de cuarto de bocel. Este calcatorium independiente presenta unas dimensiones estimadas de 2,4 por 3,55 m, con un altura máxima conservada de $55 \mathrm{~cm}$ y debió disponer de un canal de salida en su muro oriental, que permitiera el trasvase del mosto hacia los depósitos situados en el lateral oriental de la zona de estrujado. Este espacio de pisa se sitúa en una estancia más amplia, que presenta también pavimento de hormigón hidráulico con cuarto de bocel, y que interpretamos como zona de prensado. Esta sala presenta en su pavimento un recorte intencionado de forma rectangular en su esquina sureste, que se vincula con relativa claridad a la presencia de una prensa de viga. Este recorte presenta unas dimensiones de $c 1,1$ por $0,70 \mathrm{~m}$ y una orientación $\mathrm{N}-\mathrm{S}$ de su lado largo, que obliga a reconstruir la dirección de la viga con orientación E-O para permitir su correcto anclaje. En este recorte se situaría el elemento de anclaje de la cabeza del prelum, posiblemente el elemento pétreo dotado de dos anclajes hallado en 1953 por Agustín Durán que encaja en forma y dimensiones. De esta forma debemos reconstruir la localización del mecanismo de accionamiento en el lado opuesto, coincidiendo con el cierre occidental del complejo, lo que implicaría una prensa dotada de una viga con una longitud en torno a cinco metros. Al este de este espacio de extracción se localizan tres depósitos cuadrangulares simétricos y de idénticas dimensiones, que se construyen adosados a la muralla augustea. Presentan unas dimensiones de 
c 3,5 m de lado, sin que podamos determinar su capacidad ya que se encuentran completamente arrasados.

Al sur de este espacio de prensado se ha localizado un nuevo ambiente en el que aprecia la base de una posible prensa de tornillo directo. Se trata de una estructura de forma aproximadamente rectangular, con sus ángulos redondeados, que aparece remarcada por un cordón hidráulico que conecta, gracias a una canalización de plomo, con un fondo de ánfora encajado en el pavimento de la sala. Este pavimento aparece muy perdido, por lo que no podemos reconstruir el sistema empleado en la recogida del mosto. Aunque se ha interpretado un resto de solera de opus signinum situado en las inmediaciones de la base de prensado como los restos de un depósito destinado a recibir el mosto (Beltrán de Heredia 1998: 278), creemos que está interpretación debe desestimarse ya que este resto de hormigón hidráulico aparece a cota con la zona de presión. Con los datos disponibles, tampoco podemos precisar si ambas prensas se utilizaron de forma coetánea.

Respecto a los restos localizados en la zona norte, interpretados como un depósito de trasvase conectado con una canalización por la que fluiría el mosto, de acuerdo con las necesidades funcionales de la bodega y con la propia morfología de los restos localizados, creemos deben tener una funcionalidad no vinculada al ciclo de elaboración del vino. Estas estructuras son, además, estratigráficamente anteriores a la construcción de la bodega y parecen ser amortizadas en el momento en el que se construye el complejo productivo vinícola.

El elemento mejor conservado de esta bodega es su cella vinaria (Beltrán de Heredia 2001c: 70-71; 2009 y Juan 1998: 89), uno de los ejemplos mejor conocidos y estudiados de las salas de fermentación hispanas. Tiene una planta aproximadamente rectangular, con un quiebro en uno de sus lados, de $67 \mathrm{~m}^{2}$. Se ha documentado la presencia de diez dolia defossa, que pudieron haber sido once ya que el ángulo $\mathrm{N}$ de la estancia aparece arrasado por una edificación posterior. La capacidad de cada $d o$ lium ronda los 880 1, por lo que la capacidad de almacenaje total de la bodega se situaría en torno a los 9.680 1. El acceso al complejo se realizaría desde el cardo que limita el complejo productivo al este. No se ha localizado este acceso ya que apenas se conserva un tramo del muro de fachada, pero a la vista de la distribución de las estructuras productivas, este debió localizarse en el tramo comprendido entre la sala de fermentación y la sala que alberga la prensa de tornillo directo. Este espacio conserva parte de un pavimento realizado con losas de piedra, por lo que podría encontrarse a cielo abierto o parcialmente techado.
Desde el punto de vista comercial, cabe señalar dentro de las transformaciones acontecidas en la ciudad en época tardorromana, la posible construcción de nuevas tabernae vinculadas a la domus de Sant Honorat (Florensa 2011), excavada por F. Florensa, y recientemente estudiada por A. Cortés (Cortés 2011: 46-56). Estos presumibles espacios comerciales se disponen en la insula localizada inmediatamente al oeste del foro, abiertos a un decumanus minor que discurriría por la actual calle de Sant Honorat. Se trata de tres tabernae, con la típica estructura de tienda y trastienda, que pertenecen al mismo proyecto arquitectónico del resto de la casa, aunque se sitúan a una cota de circulación superior (más de $70 \mathrm{~cm}$ ) y no aparecen conectadas con las estructuras domésticas. Las tabernas parecen mantenerse en pie, sin cambios, hasta mediados o finales del s. VI, atestiguando la actividad comercial de Barcino en época tardoantigua, que se pone de manifiesto también a través de los materiales de importación presentes en los registros arqueológicos de los ss. VI-VII d.C. Creemos interesante recordar el hallazgo de un fragmento de molino harinero reutilizado en uno de los muros del siglo VI d.C de la domus.

También intramuros se localiza una nueva instalación de prensado en la esquina noroeste de la ciudad, en la misma manzana que ocupa la domus de Sant Felip Neri pero con una vinculación incierta con ella. En 2002, S. Simón dirige una pequeña intervención arqueológica en el interior de la finca número 5 de la calle de Sant Sever (Simón 2002). Se excava una superficie con una extensión en torno a $60 \mathrm{~m}^{2}$, con una estratigrafía muy alterada, en la que no se documentan estancias completas. Para nuestro análisis nos interesa el hallazgo de un lapis pedicinorum, morfológicamente similar al hallado en la bodega de la Plaza del Rei, que aparece in situ encastrado en un pavimento de opus signinum. Se trata de una pieza en piedra caliza de 86 por $70 \mathrm{~cm}$ con una altura de $30 \mathrm{~cm}$, con dos orificios cuadrangulares, de 19 por $20 \mathrm{~cm}$ y 14 por 20 , destinados a alojar las vírgenes traseras de una prensa de viga. La presión se realizaría en el espacio anterior pavimentado con opus signinum, que se ha documentado solo muy parcialmente. No podemos determinar la naturaleza del producto manufacturado ya que, como sabemos, las prensas de viga se utilizan indistintamente en la elaboración de vino y aceite (Brun 1993 y 2004: 5-36).

Extramuros constatamos también la aparición de espacios de transformación agraria a partir del s. IV d.C., con salas de prensado en los yacimientos de la villa de Sant Andreu Comtal y sobre la antigua alfarería de la calle Princesa. Posiblemente también se detectan 
este tipo de instalaciones en fase tardorromana de la villa del Pont del Treball Digne.

En el caso de la figlina de la calle Princesa, nos encontramos ante uno de los escasos ejemplos de la construcción o el mantenimiento de núcleos artesanales en los suburbia de la ciudad, que a partir del s. IV d.C. presentan una funcionalidad casi exclusiva como necrópolis (Beltrán de Heredia 2010), como sí lo indican las intervenciones extramuros de la calle Avinyó (Belmonte 2008: 91), en Sant Pau del Camp, y en todo el sector del barrio de Santa Caterina (Aguelo et al. 2005), dónde encontramos una gran zona de necrópolis de este momento (Miró 1997). Esta alfarería abandona su actividad original, destinada mayoritariamente a la elaboración de envases anfóricos, en la segunda mitad del s. II d.C. convirtiéndose en el s. III d.C. en un espacio residencial. En el s. IV d.C. se aprecia un nuevo cambio en la orientación funcional de esta zona suburbana de la ciudad, con la construcción de una bodega sobre las antiguas estructuras del alfar, que permanecerá activa hasta finales del s. V d.C.

De esta forma sobre el antiguo Ámbito 3, cubriendo una escombrera con materiales de desechos del alfar, se constata la construcción de un nuevo pavimento de tierra y cal apisonada, en el que se observan encajes semicirculares para dolia defossa en un número indeterminado (Casas y Martínez 2006: 44). Mientras, sobre la cubeta de decantación, localizada en el Ámbito 1, se constata la construcción de un depósito de opus signinum que podemos vincular con esta nueva actividad económica. Esta cubeta presenta forma aproximadamente cuadrangular y aprovecha dos de los muros del antiguo alfar para su construcción. Presenta unas dimensiones de $c$ 2,2 por 2,05 m, habiéndose conservado tan sólo unos 10 $\mathrm{cm}$ de alzado. Por último, cabe señalar la aparición de un contrapeso troncocónico con un encaje circular central, formando parte del relleno de una fosa próxima, que puede vincularse con la presencia de una prensa de viga y tornillo en esta bodega tardorromana.

Ya en el ager de Barcino, en la villa de Sant Andreu Comtal, a unos $5 \mathrm{~km}$ de la ciudad, se localiza un espacio a cielo abierto con 27 encajes para dolia defossa perfectamente alineados, fechados en el s. IV d.C. En los años 2010 y 2011, la construcción de la línea de alta velocidad en el sector de Sant Andreu ha permitido documentar diversos complejos industriales (Arroyo 2011 y 2012), entre los que se encuentra la citada bodega, que se vinculan a una villa conocida ya desde la década de los setenta del s. XX.

En el llamado Edificio A, situado a $350 \mathrm{~m}$ de la zona residencial, se han localizado diversas estancias. En el
Ámbito 3, sólo parcialmente conocido, se han documentado 27 encajes para dolia defossa perfectamente alineados, lo que nos indica una intensa actividad vitivinícola para este asentamiento desde época altoimperial, con la documentación de restos de un viñedo a través de la excavación de las zanjas destinadas a alojar las viñas (Arroyo 2011), así como también en época tardía. Tan sólo tres de estos contenedores cerámicos se documentan en posición primaria, habiendo sido el resto desmontados intencionadamente en un momento anterior a finales del s. V d.C. Las fosas, siempre de forma circular, presentan unas dimensiones comprendidas entre 0,70 y $1 \mathrm{~m}$ con una impronta máxima conservada de $45 \mathrm{~cm}$, lo que implica un soterramiento de algo menos de la mitad de la pieza. Los contenedores aparecen dispuestos en filas y columnas, habiéndose perdido su impronta en una buena parte del espacio acotado por los muros del Ámbito 3 debido a obras modernas y contemporáneas. La sala, con unas dimensiones mínimas de $160 \mathrm{~m}^{2}$, pudo haber alojado hasta 72 dolia con un diámetro máximo de $1,20 \mathrm{~m}$. A partir de los paralelos de la región, podemos reconstruir una altura de en torno a 1 o 1,2 $\mathrm{m}$ de altura para este tipo de recipientes, lo que arrojaría una capacidad de almacenamiento de 9001 para cada uno de ellos; esto implicaría una capacidad de producción de en torno a 65.0001 para esta bodega. Nos encontramos por tanto ante un alto volumen de producción, que nos indica hasta qué punto continua siendo intensa la explotación vitivinícola en el ager de Barcino en época tardorromana.

En la villa de Sant Andreu Comtal constatamos también la presencia de actividad alfarera en época tardorromana, como sabemos gracias a la localización de la subestructura de un gran horno de $4,7 \mathrm{~m}$ por 2,4 $\mathrm{m}$ y una profundidad de $40 \mathrm{~cm}$. Esta estructura aparece excavada en la arcilla, con evidencias de rubefacción en sus paredes y completamente colmatada de cenizas y carbón. No se han documentado niveles de uso vinculados a este horno que nos permitan determinar el tipo de producción cerámica elaborada.

Más próximo a la zona residencial se localiza otro edificio también con orientación artesanal, en el que se detectan tres momentos de uso caracterizados por la aparición de estructuras de combustión superpuestas. De la primera fase, se constata la aparición de la base de una estructura de combustión, de la que se conserva la solera de la arcilla rubefactada, vinculada a un nivel de uso caracterizado por la presencia de carbón y ceniza. De la segunda fase, se observa la aparición de cuatro pequeños hornos dispuestos en torno a un pilar central. Se han conservado las bases de arcilla 
rubificada de estos hornos de $c 1 \mathrm{~m}$ de diámetro, y parcialmente el alzado de dos de ellos, uno realizado con paredes de arcilla y el otro con dos tegulae dispuestas verticalmente. A este momento se vincula un plano de uso también caracterizado por la presencia de carbón y ceniza y dos agujeros de poste. Todavía se detecta un tercer nivel de incineración, aunque en este caso no quedan restos de los elementos estructurales de combustión. No se detectan restos de escorias de metal, vidrio o cerámica que nos permitan determinar la funcionalidad de este taller.

Por último dentro, también, del ager de la ciudad, distante tan sólo 1.300 metros en línea recta de la villa de Sant Andreu Comtal, nos encontramos con la recientemente excavada villa del Pont del Treball Digne, aún en proceso de estudio bajo la dirección de D. Alcubierre y J. Ardiaca (Alcubierre, Hinojo y Rigo 2014). En este asentamiento, con una clara orientación vinícola en época altoimperial, se detectan en su fase tardorromana estructuras productivas vinculadas con la explotación agraria del territorio.

En 1989, se llevan a cabo una serie de sondeos en la Plaza de Sant Miquel para intentar completar la información de la excavación de 1960. Dentro de la secuencia estratigráfica documentada se señala el hallazgo de varios muros, un horno y un pozo fechados en el s. V d.C. (Raya y Miró 1991). También en la domus del Arxiu Administratiu se detecta la construcción de un horno vinculado con actividades artesanales, en este caso fechado en el s. IV d.C. Esta estructura de combustión se ubica en el antiguo praefurnio de las termas (Martín, Miró y Revilla 2000). Se trata de una estructura de planta circular de 1,5 $\mathrm{m}$ de diámetro por 2,1 de diámetro exterior, con la base de la cámara de combustión hecha con fragmentos de cerámica rubificados, vinculados según J. Beltrán de Heredia a abundantes escorias de vidrio, por lo que se interpreta como un horno de vidriero. Por su parte, en la excavación de la domus de San Felip Neri, J. Beltrán de Heredia señala también la existencia de escorias de vidrio en contextos de los ss. VI y VII, junto a una estructura muy arrasada que podría ser interpretada como un horno de vidrio (Beltrán de Heredia 2013: 59).

Por último, también con posterioridad al s. V d.C., se fechan una serie de almacenes a cielo abierto en silos ubicados extramuros en las puertas de acceso oriental y occidental de la ciudad, que debido a su capacidad podrían vincularse con espacios de mercado. Especialmente significativos son los restos localizados en el suburbium occidental, en la Plaza Nova y en la calle Capellans, así como los documentados de la calle
Ripoll, 25 (Miró 2005, Blasco et alii 1992, Nogués y Forés 2004 y Triay 2009). Se trata de estructuras de c $1 \mathrm{~m}$ de diámetro que deben vincularse con el acaparamiento de rendimientos agrarios del tipo cereal o leguminoso. Así, en este suburbium occidental se han constatado hasta el momento más de 100 estructuras negativas tipo silo: 50 en la Plaça Nova, 46 en la c/ Capellans y 10 en la c/ Ripoll. Este tipo de fosas de almacenamiento se localiza también, con cronologías similares, en el acceso sur de la ciudad en los entornos del Pati d'en Llimona. Se detectan también este tipo de estructuras intramuros en el caso de la domus de Sant Honorat, donde constatamos la construcción de silos asociados a una posible zona de cultivo interior vinculada con un pequeño hábitat.

\section{CONCLUSIONES}

En la intervención desarrollada en la Calle de Avinyó, se localizan los restos de una domus y parte del intervallum de la ciudad, que es ocupado en la segunda mitad del s. III d.C. o a principios del s. IV d.C. por una panadería. Se constata la construcción de un horno de calentamiento directo de forma cuadrangular, de estructura interna circular con cubierta cupulada, que presenta una meta reutilizada dispuesta en su fachada, flanqueando, posiblemente, el acceso a la cámara de calor. Este elemento pétreo aparece volteado y vaciado, siendo utilizado como un pequeño contenedor, bien destinado a albergar agua o bien utilizado como cenicero en la limpieza del horno, tal y como constatamos en los ejemplos pompeyanos. El molino presenta una forma troncocónica y por sus características se identifica con claridad como una meta, o durmiente, de un molino pompeyano de tracción animal, que incluiríamos en el tipo 451d, variante XXIX (Longepierre 2012: 89). Los estudios pétreos realizados sobre la pieza (Gimeno et al. 2010) permiten, además, situar su origen en canteras cercanas a la ciudad italiana de Orvieto, en Etruria.

Junto con esta instalación, a finales del s. III o principios del s. IV d.C. detectamos en la ciudad de Barcino una intensa actividad constructiva, tanto desde el punto de vista público, como de la edilicia privada, con importantes reformas de carácter suntuario en prácticamente todas las domus conocidas de la ciudad. Estas reformas incluyen también el nacimiento de talleres urbanos artesanales, vinculados o no a espacios residenciales. Se configuran en este momento dos grandes sectores artesanales en el interior de la ciudad, que 
aglutinan espacios productivos de distinta naturaleza (Plaza de Sant Miquel y Plaza del Rei). También intramuros se localiza una nueva instalación de prensado en la esquina noroeste de la ciudad, en la misma manzana que ocupa la domus de Sant Felip Neri.

Frente a este incremento de los espacios productivos intramuros asistimos a la práctica desaparición de la actividad industrial en los suburbia de la ciudad, que coincide con la construcción de nuevos espacios de producción agropecuaria en las villae situadas en el ager de Barcino. Así constatamos la construcción de nuevas bodegas en la villa de Sant Andreu Comtal y sobre la antigua alfarería de la calle Princesa. Posiblemente también se detecta un espacio destinado al prensado en la villa del Pont del Treball Digne.

Ya a partir del s. V d.C. las evidencias del trabajo artesanal descienden significativamente, debido a la consolidación de un modelo de ocupación urbano en el que se priman los espacios polifuncionales carentes de elementos estructurales significativos. De esta forma, intramuros sólo hemos podido localizar tres talleres en funcionamiento en época tardoantigua, los localizados respectivamente en la Plaza de Sant Miguel, las domus de Sant Felip Neri y Arxiu Administratiu.

\section{Agradecimientos}

Este estudio ha sido financiado por el Ayuntamiento de Barcelona y se inscribe dentro de las actuaciones llevadas a cabo dentro del Plan Barcino.

En relación a la domus Avinyó, son diversos los especialistas que han intervenido en la investigación de los diferentes elementos. Cabe destacar el estudio del conjunto pictórico llevado a cabo por la Dra. Alicia Fernández y Lorenzo Suárez, de la Universidad de Murcia y el estudio del pavimento de mosaico realizado por la Dra. Irene Mañas, de la UNED. También hemos de agradecer y destacar el asesoramiento de la Dra. Virginia García Entero para la interpretación de la domus y en la identificación de los mármoles del pavimento de opus sectile. También queremos agradecer la colaboración de Encarna Cobo y Jordi Ramos, en la elaboración de este artículo.

Respecto a la musealización del espacio de la Domus Avinyó nos gustaría resaltar el proyecto arquitectónico realizado por el estudio VORA y el museográfico del estudio STOA, ambos dirigidos desde el Servicio de Arqueología de Barcelona. Señalar, así mismo, los trabajos de restauración realizados por la empresa Gamarra García.
Respecto a las imágenes publicadas en este artículo nos gustaría agradecer la cesión de la figura 2 a J. García Biosca y a la empresa Atics S.L. la realización de la figura 9. Por su parte el plano de la figura 1 ha sido elaborado sobre el trabajo preliminar de Bertha Durà y Alex Moreno.

\section{BIBLIOGRAFÍA}

Aguelo, J.; Huertas, J. y Puig, F. (2005): "Santa Caterina de Barcelona: assaig d'ocupació i evolució". Quaderns d'Arqueologia i Història de la Ciutat de Barcelona, Quarhis 01: 11-43.

Alcubierre, D.; Hinojo, E. y Rigo, A. (2014): "Primers resultats de la intervenció a la vil·la romana del Pont del Treball a Barcelona". Tribuna d'Arqueologia 2011-2012: 372-398.

Anderson, T.J. (2014): “Moleras en la Península Ibérica: una primera clasificación de las canteras de molinos". Revista d'Arqueologia de Ponent 24: 157-174.

Anderson, T.J. (2016): Turning Stone to Bread: A Diachronic Study of Millstone Making in Southern Spain, Southampton.

Archetti, G. (ed.) (2015): La Civiltà del Pane. Storia, tecniche e simboli dal Mediterraneo all'Atlantico. Atti del convegno internazionale di studio. Brescia (2014), Spoleto, Fondazione Centro italiano di studi sull'alto Medioevo.

Arroyo, S. (2011): "LAV sector de Sant Andreu". Anuari d'arqueologia $i$ patrimoni de Barcelona 2010: 45-52.

Arroyo, S. (2012): "LAV sector de Sant Andreu". Anuari d'arqueologia $i$ patrimoni de Barcelona 2011: 88-95.

Balil, A. (1961): Las murallas romanas de Barcelona, Madrid.

Belmonte, C. (2008): 'L'ocupació de l'extrem sudoest del suburbium de Barcino entre elssegles I-IV $\mathrm{dC}$ : les troballes del carrerd'Avinyó". Quaderns d'Arqueologia i Història de la Ciutat de Barcelona, época II, 4: 90-105.

Beltrán de Heredia J. 1999: “La elaboración del vino en el mundo romano: una instalación urbana de producción de vino en Barcino", en Vi a l'Antiguitat II. Economia, producció i comerç al Mediterrani occidental: II Col·loqui Internacional d'Arqueologia Romana, actes: 277-281. Badalona (6-9 de mayo 1998), Museo de Badalona.

Beltrán de Heredia, J. (2001a): "Fullonica y tinctoria. Telas, tintes y lavados en la antigua colonia 
romana", en De Barcino a Barcinona (siglos I-VII). Los restos arqueológicos de la Plaza del Rey de Barcelona: 48-57. Barcelona, Museu de Historia de la Ciudad.

Beltrán de Heredia, J. (2001b): "Una factoría de garum y salazón de pescado en Barcino", en De Barcino a Barcinona (siglos I-VII). Los restos arqueológicos de la Plaza del Rey de Barcelona: 58-65. Barcelona, Museu de Historia de la Ciudad.

Beltrán de Heredia, J. (2001c): “Uva y vino a través de los restos arqueológicos: la producción de vino en Barcino", en De Barcino a Barcinona (siglos IVII). Los restos arqueológicos de la Plaza del Rey de Barcelona: 66-71. Barcelona, Museu de Historia de la Ciudad.

Beltrán de Heredia, J. (2007): “Cetariae bajo imperiales en la costa catalana: el caso de Barcino", en L. Lagóstena et al. (coords.), Salsas y salazones de pescado en Occidente durante la Antigüedad: 277-284. BAR. International Series, 1986. Cadiz, 7-9 de noviembre de 2005. Oxford: John and Erica Hedges Ltd

Beltrán de Heredia, J. (2009): "Premses vineres i instal.lacions vinícoles a "Barcino", en C. Carreras, J. Guitart y A. López Mullor (coords.), Marques $i$ terrisseries d'àmfores al pla de Barcelona, vol. 1: 119-130. Barcelona: Institut d'Estudis Catalans; Tarragona: Institut Català d'Arqueologia Clàssica

Beltrán de Heredia, J. (2010): "La cristianización del suburbium de Barcino", en D. Vaquerizo, (ed.), Las áreas suburbanas en la Ciudad Histórica. Topografia, usos, función. Monografias de arqueología cordobesa, 18: 363 - 395. Cordoba, Universidad de Cordoba.

Beltrán de Heredia, J. (2013): “Barcino de colònia romana a sede regia visigoda, medina islàmica i ciutat comtal: una urbs en transformació". Quaderns d'Arqueologia i Història de la Ciutat de Barcelona, época II, 9: 16-118.

Beltrán de Heredia, J. (2014): “Barcelona, colonia en la "Hispania" romana y "sede regia" en la "Hispania" visigoda", en D. Vaquerizo Gil, J.A. Garriguet y A. León (coords.), Ciudad y territorio: transformaciones materiales e ideológicas entre la época clásica y el Altomedioevo: 325-338. Córdoba, Universidad de Cordoba.

Blasco, M.; Granados, J. O.; Laorden, V.; Miró, M.; Prada, J. L.; Piquer, E.; Puig, F. y Rovira, C. (1992): L'Avinguda de la Catedral: de l'ager de la colònia Barcino a la vilanova dels arcs. Barcelona, Ayuntamiento de Barcelona. Regidoria d'Edicions i Publicacions.
Bonnet, C. y Beltrán de Heredia, J. (2001): “Origen y evolución del conjunto episcopal de Barcino: de los primeros tiempos cristianos a época visigoda", en De Barcino a Barcinona (siglos I-VII). Los restos arqueológicos de la Plaza del Rey de Barcelona: 74-95. Barcelona, Museu de Historia de la Ciudad

Bordas, A. y Torres, G. (2006): Memòria conjunta de les intervencions a Ampliació de l'avinguda Cambó. Barcelona, memoria de intervención inédita.

Brun, J.P. (1993): "La discrimination entre las installations oléicoles et vinicoles", en La production $d u$ vin et de l'huile en Mediterranée, BCH Suppl. 26: 511-537. Paris. Escuela Francesa de Atenas.

Brun, J.P. (2000): "The production of perfumes in Antiquity. The cases of Delos and Paestum". American Journal of Archaeology 104: 277-308.

Brun, J.P. (2004): Archéologie du vin et l'huile. De la préhistoire à l'époque hellénistique. Paris, Collection des Hespérides.

Brun, J.P. y Monteix, N. (2009): "Les parfumeries en Campanie antique", en J.P. Brun (ed.), Artisanats antiques d'Italie et de Gaule. Mélanges offerts à Maria-Francesca Buonaiuto: 115-133. Nápoles, Centre Jean Bérard

.Buffone, L.; Lorenzoni, S.; Pallara, M. y Zanttin, E. (1999): "Le macine rotatorie in rocce vulcaniche di Pompei". Rivista di Studi Pompeiani 10: 117-130.

Buonopane, A. (2015): "Il mulino, una macchina dell'antichità", en G. Archetti (ed.), La Civiltà del Pane. Storia, tecniche e simboli dal Mediterraneo all'Atlantico. Atti del convegno internazionale di studio: 67-82. Brescia (2014), Spoleto, Fondazione CISAM Bustamente, M. (2013): "El trabajo artesanal en Augusta Emerita durante los ss. I-IV d. C.". Zephyrus 72: 113-138.

Bustamante, M.; Salido, J. y Gijón, E. (2014): “La panificación en la Hispania romana", en M. Bustamante y D. Bernal (eds.), Artífices idóneos. Artesanos, talleres y manufacturas en Hispania:319-353. Mérida, Consejo Superior de Investigaciones Cientifícas.

Casas, J. (2009): "Una terrisseria del pla de Barcelona: l'excavació del carrer de la Princesa, número 21", en C. Carreras, J. Guitart y A. López Mullor (coords.), Marques $i$ terrisseries d'àmfores al pla de Barcelona, vol. 1: 63-88. Barcelona: Institut d'Estudis Catalans; Tarragona: Institut Català d'Arqueologia Clàssica

Casas, J. y Martínez, V. (2006): "El taller ceràmic d' època romana del Carrer Princesa de Barcelona. Estudi Arqueològic de les restes i estudi arqueomètric 
del material ceràmic". Quaderns d'Arqueologia i Història de la Ciutat de Barcelona, época II, 2: 36-59.

Chartrain, A. (2015): "Il mulino, una macchina dell'antichità", en G. Archetti (ed.), La Civiltà del Pane. Storia, tecniche e simboli dal Mediterraneo all'Atlantico. Atti del convegno internazionale di studio: 433-468. Brescia (2014), Spoleto, Fondazione CISAM

Cortés, A. (2011):'L'arquitectura domèstica de la ciutat romana de Barcino". Quaderns d'Arqueologia i Història de la Ciutat de Barcelona, época II, 7: 16-66.

Fernández, A. y Suárez, L. (2014): “La representación del rapto de Ganímedes en la habitación 3 de la domus de Avinyó (Barcelona): un unicum de la pintura provincial romana". Quaderns d'Arqueologia i Història de la Ciutat de Barcelona, época II,10: 122-139.

Florensa, F. (2011): L'intervenció arqueológica al carrer Sant Honorat. Ciutat Vella-Barcelona (Barcelonés). Memoria Inédita. (Fondo Centre de Documentació del Servei d'Arqueologia). Q160.011/01 (h.1)

Florensa, F. y Gamarra, A. (2006): “L'excavació del jaciment arqueológic del carrer de Sant Honorat, 3 Barcelona". Tribuna d'Arqueologia 2003-2004: 189-209.

Gimeno, D.; Aulinas, M.; Fernández-Turiel, M.; Pugès, M. y Novembre, D. (2009): “Archeometric evidence of trade of leucocite-bearing volcanic-made Roman mills of Pompeian style in NE Hispania (Spain)". Geochimica Cosmochimica Acta, volume 73, 13, suplement A: 437.

Gimeno, D.; Aulinas, M.; Fernández-Turiel, M.; Pugès, M. y Novembre, D. (2010): "Molins rotatoris romans". Anuari d'Arqueologia i Patrimoni de Barcelona, 2009: 234-235.

Granados, J. O.; Recasens, M. y Tarradell, N. (1993): "Palau Centelles". Anuari d'intervencions arqueològiques 1982-1989, Època romana-Antiguitat tardana, campanyes 1982-1989: 104.

Huertas, J. (2016): “Avinyó, 15”. Anuari d'arqueologia i patrimoni de Barcelona 2014:.92-94.

Juan-Tresserras, J. (1999): "El cultivo de la vid y la elaboración del vino en la Península Ibérica en la Antiguedad. Aportaciones de los análisis de residuos", en Vi a l'Antiguitat II. Economia, producció i comerç al Mediterranioccidental: II Col·loqui Internacional d'Arqueologia Romana, actes: 8792. Badalona, 6 a 9 de mayo de 1998. Museo de Badalona.
Longepierre, S. (2012): Meules, moulins et meulières en Gaule méridionale du IIe s. av. J.-C auVIIe. Ap. J.-C., Montagnac, Monique Mergoil.

Martín, A; Miró, N. y Revilla, E. (2000): “El complejo termal privado de la domus de la calle Bisbe Caçador de Barcelona", en Termas romans de occidente del imperio: II Coloquio Internacional de Arqueología en Gijón: 171-178. Gijón, VTP editorial.

Mayeske, B.J.B. (1972): Bakeries, Bakers, and Bread at Pompeii: a Study in Social and Economic History. Maryland, Universidad de Maryland.

Miró, C. y Puig, F (2000): "Edificios termales públicos y privados en Barcino", en Termas romanas en el occidente del imperio: II Coloquio Internacional de Arqueología en Gijón: 171-178. Gijón, VTP editorial.

Miró, C. (2005): "Balanç de l'activitatarqueològica a la ciutat (setembre 2003 - desembre 2004)". Quaderns d'Arqueologia i Història de la Ciutat de Barcelona, época II, 1: 135-149.

Miró, C. (2014): "La muralla romana en el marc del Pla Barcino. Projectes i resultats de l'any 2013". Quaderns d'Arqueologia i Història de la Ciutat de Barcelona, época II, 10: 205-206.

Miró, C. (2015): "Pla Barcino. La muralla romana entre les torres 27 i 28. Resultats arqueològics". Quaderns d'Arqueologia i Història de la Ciutat de Barcelona, época II, 11: 205-206.

Miró, N. (1997): Memòria de la intervenció realitzada als carrers de l'Argenteria i Manresa de Barcelona (Barcelonès). Memoria Inédita. (Fondo Centre de Documentació del Servei d'Arqueologia. Q160.2004 (h.1)

Monteix, N. (2009): "Pompéi, Pistrina: recherches sur les boulangeries de l'Italie romaine. 2008". Mélanges de l'École Française de Rome. Antiquité 121, 1: 322-335.

Monteix, N. (2010): "Pompéi, Pistrina: recherches sur les boulangeries de 1'Italie romaine. 2009". Mélanges de l'École Française de Rome. Antiquité 122, 1: 275-283.

Monteix, N.; Aho, S.; Coutelas, A.; Garnier, L.; Matterne, V.; Zanella, S.; Albano, V.; Bukowiecki, E.; Derreumaux, M.; Hartz, C.; Letellier, E.; Mignot, O. y Ranucci, S. (2011): "Pompéi, Pistrina: recherches sur les boulangeries de l'Italie romaine. 2010". Mélanges de l'École Française de Rome. Antiquité 123, 1: 306-313.

Monteix N.; Aho, S.; Garnier, L.; Hartz, C.; Letellier, E. y Zanella, S. (2012): "Chronique des activités archéologiques de l'École française de Rome [En ligne]", en Les cités vésuviennes, URL: http://cefr. 
revues.org/328, mis en ligne le 19 décembre 2012 (consultado el 30 de junio de 2015).

Monteix, N.; Zanella, S.; Aho, S.; Macario, R. y Proudfoot, E. (2013): "Pompéi, Pistrina. Chronique des activités archéologiques de l'École française de Rome [En ligne]", en Les cités vésuviennes, URL: http://cefr.revues.org/954, mis en ligne le 23 mai 2013 (consultado el 30 de junio de 2015).

Monteix, N.; Aho, S.; Coutelas, A. y Zanella, S. (2014): "Pompéi, Pistrina. Chronique des activités archéologiques de l'École française de Rome [En ligne]", en Les cités vésuviennes, URL : http://cefr.revues. org/1242, mis en ligne le 30 septembre 2014 (consultado el 29 de junio de 2015).

Nogués, J. y Forés, C. (2004): Memòria de l'excavació arqueològica realitzada al solar de la finca dels carrers Capellans, núm. 4 i Sagristrans, núms. 2-6 de Barcelona. Barcelona. Memoria Inédita. (Fondo Centre de Documentació del Servei d'Arqueologia), Q160.04/04(h.1)

Pallares, F. (1969): "Las excavaciones de la plaza de San Miguel y la topografía romana de Barcino". Cuadernos de Arqueología e Historia de la Ciudad 13: 5-42.

Peacock, D.P.S. (1980): “The Roman millstone trade: a petrological sketch”. World Archaeology 12: 43-53.

Peacock, D.P.S. (1986): "The production of Roman millstones near Orvieto, Umbria, Italy". Antiquaries Journal 66: 45-51.

Peacock D.P.S. (1989): “The mills of Pompeii". Antiquity 239 (63): 205-214.

Peña, Y. (2008): "La producción de vino en contextos eclesiásticos tardoantiguos hispanos", en J. Blánquez, y S. Celestino (eds.), El vino en época tardoantigua y medieval: 343-357. Murcia, Universidad Autónoma de Madrid.

Peña, Y. (2010): Torcularia. La producción de vino y aceite en Hispania. Tarragona, UNED.

Peña, Y. (2011-2012): "Variantes tecnológicas hispanas en los procesos de elaboración de vino y aceite en época romana", en J.M. Noguera y J. A. Antolinos (eds.), De vino et oleo hispaniae. Áreas de producción y procesos tecnológicos del vino y el aceite en la Hispania romana. Coloquio Internacional. Anales de Prehistoria y Arqueología de la Universidad de Murcia 27-28: 37-58. Murcia, 5 a 7 de mayo 2010. Universidad de Murcia, el Campus de Excelencia Internacional Mare Nostrum, la Fundación Cajamurcia y la UNED.

Perich, A. (2014): "Barcino entre los siglos IV y VI d. C. Transformaciones y ascenso de una ciudad mediterránea durante la Antigüedad Tardía”. Espacio, tiempo y forma. Serie I, Prehistoria y arqueología 7: 61-96.

Procopiou, H. y Treuil, R., (dirs.) (2002): Moudre et broyer. L'interprétation fonctionnelle de l'outillage de mouture et du broyage dans la Préhistoire et l'Antiquité, t. II: Archéologie et Histoire: du Paléolithique au Moyen Âge, Revue archéologique $d u$ Centre de la France. Vol.42, núm.1. Paris.

Puig, F. y Rodà, I. (2010): Les muralles de Barcino. Noves aportacions al coneixement de l'evolució dels seus sistemes de fortificació. Barcelona, Museo de Historia de la Ciudad.

Ramos, J. (2014): "Muralla romana. Carrer del Sostinent Navarro". Anuari d'arqueologia i patrimoni de Barcelona 2012: 126-130.

Ramos, J. (2015): "Muralla romana. Torres 27 i 28". Anuari d'arqueologia $i$ patrimoni de Barcelona 2013: 100-105.

Ravotto, A. (2014): "La muralla romana de Barcelona. Una empresa de finals del segle III". Quaderns d'Arqueologia i Història de la Ciutat de Barcelona, época II, 10: 140-162.

Raya, M. y Miró, B. (1991): "Excavació arqueològica a la plaça de Sant Miquel". Tribuna d'arqueologia 1989-1990: 157-158.

Salido, J. (2011): "El almacenamiento de cereal en los asentamientos rurales hispanorromanos", en J. Arce y B. Goffaux (eds.), Horrea d'Hispaniae et de la Méditerranée romaine: 127-142. Madrid, Casa de Velazquez.

Salido, J. y Bustamante, M. (2014): Pistrina Hispaniae. Panaderías, molinerías y artesanado alimentario en Hispania. Montagnac, Editions Monique Mergoil.

Simón, S. (2002): Informe sobre els resultats de la intervenció arqueológica realitzada a la finca núm. 5 del c. Sant Sever i núm. 2-4 de Sant Felip Neri de Barcelona. Barcelona. Memoria Inédita. (Fondo Centre de Documentació del Servei d'Arqueologia), Q160.026/99(h.1)

Travesset, M. (1960-1961): Excavació del subsòl de l'àrea destinada a la construcció del nou edifici destinat a oficines de l'ajuntament de Barcelona, durant els anus 1960-1961. Barcelona, Memoria Inédita. (Fondo Centre de Documentació del Servei d'Arqueologia),

Triay, V. (2009): Memòria de la intervenció arqueológica preventiva efecturada a la finca Ripoll 25, Capellans, 10-16. Districte de Ciutat Vella. Barcelona. Memoria Inédita. (Fondo Centre de Documentació del Servei d'Arqueologia), Q160.094/03(h1) 
Vilardell, A. (2006): Memòria conjunta de la intervenció arqueologica del carrer Avinyó núm $15 i$ del carrer Pou Dolç núm 4 de Barcelona (Barcelonès). Barcelona. Memoria Inédita. Fondo Centre de Documentació del Servei d'Arqueologia. Q160.094/03(h1).

Vilardell, A. (2008): "Les restes romanes del carrer Avinyó dins l'urbanisme de Barcino". Ex novo. Arqueologia Urbana 77: 59-79.

Williams, D. y Peacock, D. (dir) (2011): Bread for the people: The Archaeology of Mills and Milling. Proceedings of a colloquium held in the British School at Rome. Roma (2009), Southampton, Oxford: Archeopress.

Williams-Thorpe, O. (1988): "Provenancing and archaeology of Roman millstones from the Mediterranean area". Journal of Archaeological Science 15: 253-305.

Wilson, A. y Schörle, K. (2009): “A baker's funerary relief from Rome". Papers of the British School at Rome 77: 101-123.

www.orviamm.com/ (consultado el 23 de marzo de 2016). www.laciviltadelpane.it/ (consultado el 23 de marzo de 2016). 